Portland State University

PDXScholar

\title{
Modeling the Impact of Roof Reflectivity, Integrated Photovoltaic Panels and Green Roof Systems on the Summertime Heat Island
}

Adam Scherba

Portland State University

Follow this and additional works at: https://pdxscholar.library.pdx.edu/open_access_etds Let us know how access to this document benefits you.

\section{Recommended Citation}

Scherba, Adam, "Modeling the Impact of Roof Reflectivity, Integrated Photovoltaic Panels and Green Roof Systems on the Summertime Heat Island" (2011). Dissertations and Theses. Paper 246.

https://doi.org/10.15760/etd.246

This Thesis is brought to you for free and open access. It has been accepted for inclusion in Dissertations and Theses by an authorized administrator of PDXScholar. Please contact us if we can make this document more accessible: pdxscholar@pdx.edu. 
Modeling the Impact of Roof Reflectivity, Integrated Photovoltaic Panels and Green Roof Systems on the Summertime Heat Island

by

Adam J. Scherba

A thesis submitted in partial fulfillment of the requirements for the degree of

\author{
Master of Science \\ In \\ Mechanical Engineering
}

Thesis Committee:

David Sailor, Chair

Graig Spolek

Huafen $\mathrm{Hu}$

Portland State University

(C)2011 


\begin{abstract}
This study presents the results of a modeling effort to explore the role that sustainable roofing technologies play in impacting the rooftop energy balance, and the resultant net sensible heat flux into the urban atmosphere with a focus on the summertime urban heat island. The model has been validated using data from a field experiment. Roofing technologies explored include control dark membrane roof, a highly reflective (cool) roof, a vegetated green roof, and photovoltaic panels elevated above various base roofs. Energy balance models were developed, validated with experimental measurements, and then used to estimate sensible fluxes in cities located in six climate zones across the US.

To evaluate the impact on urban air temperatures, a mesoscale meteorological model was used. Sensible flux profiles calculated using a surface energy balance were used as inputs to the mesoscale model. Results for a 2-day period in Portland, OR are analyzed.

Average findings indicate that the black roof and black roof with PV have the highest peak daily sensible flux to the environment, ranging from 331 to 405 $\mathrm{W} / \mathrm{m}^{2}$. The addition of PV panels to a black roof had a negligible effect on the peak flux, but decreased the total flux by an average of $11 \%$. Replacing a black roof with a white or green roof resulted in a substantial decrease in the total sensible flux. Results indicate that if a black membrane roof is replaced by a PV covered white or a PV covered green roof the corresponding reduction in total sensible flux is on the order of $50 \%$.
\end{abstract}


Mesoscale modeling results indicate peak daytime temperature reduction of approximately $1^{\circ} \mathrm{C}$ for both white and green roofs. However, there is a nighttime penalty on the order of $0.75^{\circ} \mathrm{C}$ for the green roof case, which has been attributed to the additional thermal storage of a green roof. Findings also reveal that the addition of PV panels to a roof has a nighttime cooling effect. This is most pronounced on a white roof, with magnitudes of $1^{\circ} \mathrm{C}$.

The methodology developed for this analysis provides a foundation for evaluating the relative impacts of roof design choices on the urban climate and should prove useful in guiding urban heat island mitigation efforts. 


\section{Acknowledgements}

I would like to thank David Sailor for his ongoing support of my research and providing funding for this work. Without David's previous work developing the EnergyPlus Green Roof Module and mesoscale modeling flux perturbation capabilities this work would not have been possible.

I would also like to thank Seth Moody for his assistance in establishing the Science Building 2 rooftop instrumentation and data collection systems.

Funding for this work was provided through grants and materials provided by: the National Science Foundation, Oregon BEST, Portland General Electric, Solar World, and the city of Portland. 


\section{Table of Contents}

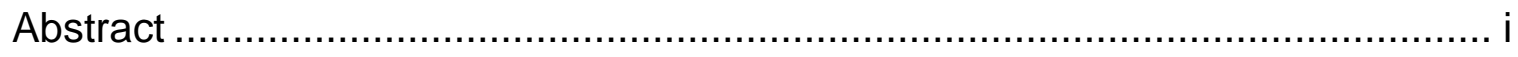

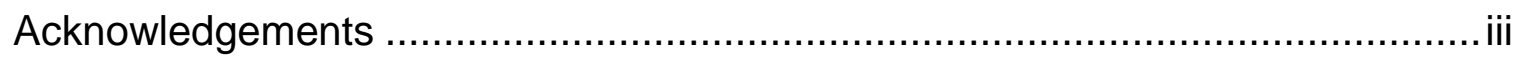

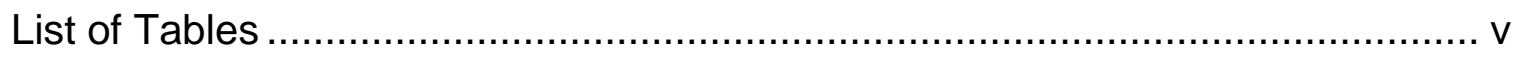

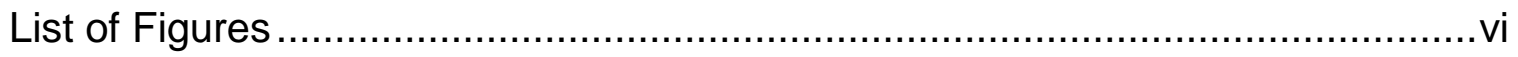

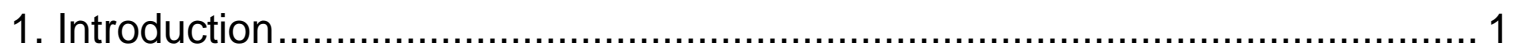

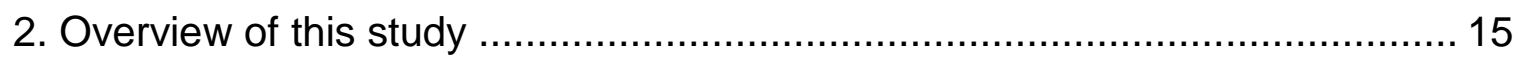

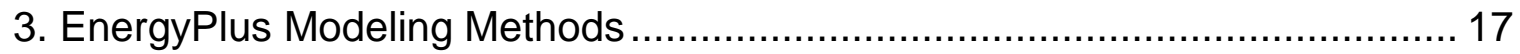

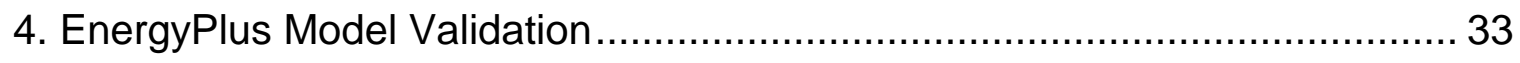

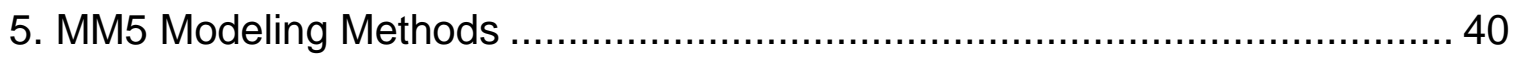

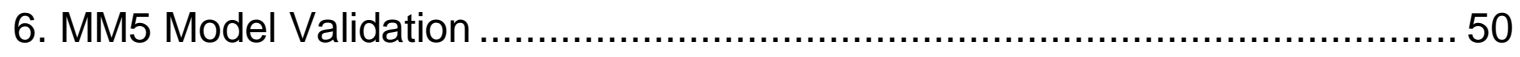

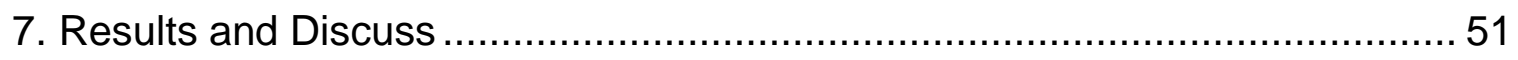

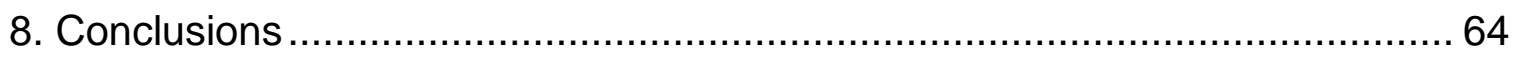

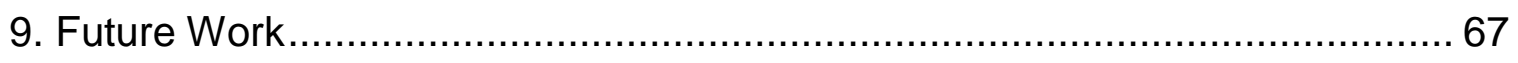

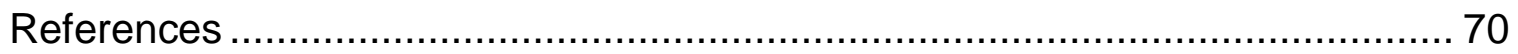




\section{List of Tables}

Table 1: Change in heating degree days (HDD)

and cooling degree days (CDD) due to the UHI

10

Table 2: Comparison of various roof types

21

Table 3: Cities chosen for EnergyPlus analysis

Table 4: Portland, OR weather observation during

validation period in 2010

Table 5: Grid size and timesteps used for all

simulations

Table 6: Default parameters assigned to urban

land use category in MM5 model

Table 7: Average roof albedo for three cities

Table 8: Reduction in roof temperature due to addition of PV panels 


\section{List of Figures}

Figure 1: Typical urban heat island profile $\quad 4$

Figure 2: Comparison between the urban and rural surface energy 6 balance.

Figure 3: Surface energy balance for an unshaded roof 15

Figure 4: Surface energy balance for a shaded roof 15

Figure 5: Test matrix of roof types studied with naming convention 16 defined for each roof type combination.

Figure 6: Coupling of building energy and mesoscale models 17

Figure 7: Schematic overview of EnergyPlus simulation modules 18

Figure 8: Map of U.S. climate zones 20

Figure 9: Calculation procedure for sensible heat fluxes on a 27 traditional roof

Figure 10: Calculation procedure for flux calculations for the PVshaded portion of a roof

Figure 11: Geometry of rooftop PV array 29

Figure 12: Solar geometry used to determine ratio of shaded to 32 unshaded roof area

Figure 13: Procedure for calculating the net sensible flux for each roof element

Figure 14: Experiment layout used for model validation

Figure 15: Modeled vs. measured PV surface temperature 37

Figure 16: Measured temperature on shaded roof vs. model with varying view factors

Figure 17: Modeled vs. measured temperature for an unshaded white roof

Figure 18: Modeled vs. measured temperature for a shaded black roof 
Figure 19: MM5 modeling system.

Figure 20: Five-domain nesting used for MM5 simulations.

Figure 21: Domain 5 terrain height topographic map centered on Portland.

Figure 22: Domain 5 USGS 24 category land use

Figure 23: Satellite imagery used to estimate proportion of urban land with roof cover

Figure 24: Representative flux perturbation profile used for MM5 model input

Figure 25: Validation of MM5 model with historic meteorological observations from PDX Airport

Figure 26: Temperature Profile for Chicago

Figure 27: Flux Profile for Chicago

Figure 28: (a) Summer mean peak daily flux (b) Summer mean total daily flux

Figure 29: Summer mean percent reduction in: (a) peak, (b) total, daily flux from black roof levels.

Figure 30: PV UHI Penalty - (a) peak flux, (b) total flux

Figure 31: Impact of PV panels or black roof membrane temperature

Figure 32: Impact of PV panels or white roof membrane temperature

Figure 33: Impact of PV panels or green roof membrane temperature

Figure 34: Modeled near-surface air temperature

Figure 35: Change in near-surface air temperature due to white roof

Figure 36: Typical flux profile of a white and white PV roof on a hot summer day. 
Figure 37: Change in near-surface air temperature due to green roof 


\section{Introduction}

When considering sustainable urban development and building practices, rooftops may not be the first thing that comes to mind. Roofing technology is often not very exciting or innovative, and is seldom considered until things go wrong and a roof starts to leak. However, rooftops are playing an increasingly important role in urban sustainability efforts. Various roofing technologies have been promoted for reducing stormwater runoff, generating electricity, reducing building energy consumption, or mitigating the urban heat island (UHI). While some prior research has explored the efficacy of such technologies, these studies are typically limited to a single technology or a specific location (climate). They also tend to lack a quantitative connection between the rooftop surface energy balance and the urban climate system.

In response to the numerous research questions surrounding roofing technology, Portland State University (PSU) was awarded a National Science Foundation grant to study the topic. This led to establishment of the PSU Green Roof Integrated Photovoltaic (GRIPV) research facility. The goal of GRIPV is to study the combination of green roof and photovoltaic systems in the urban rooftop environment of Portland, OR. This study includes research into three basic questions:

1. What are the relationships between green roof evapotranspiration, PV energy production, and green roof carbon gain?

2. How do PV arrays and green roofs impact building energy consumption? 
3. What is the impact of roof-mounted PV arrays and green roofs on the development of the urban heat island?

The focus of the present study is the third GRIPV research area. The following report presents a quantitative analysis of how different roofing technologies (including green roofs and PV arrays) impact the urban heat island.

\subsection{Urban Heat Island Overview}

\subsubsection{Surface Energy Balance}

Consideration of the surface energy balance equations is helpful in better understanding $\mathrm{UHI}$ causes and mitigation strategies. The general surface energy balance for a flat, homogeneous, horizontal surface is given by:

$$
\alpha_{s} Q+\alpha_{s} q+\alpha_{L} L+Q_{f}=\varepsilon \sigma T_{s}^{4}+h_{C}\left(T_{s}-T_{a}\right)+\left.k \frac{d T_{s}}{d z}\right|_{z=0}+\lambda E
$$

where $\alpha_{\mathrm{S}}$ and $\alpha_{\mathrm{L}}$ are absorptivities for short and long wave radiation, $\mathrm{Q}$ is direct short wave radiation flux, $q$ is diffuse shortwave radiation flux, $L$ is incoming long wave radiation flux, $Q_{f}$ is anthropogenic heat flux, $\varepsilon$ is surface long wave emissivity, $\sigma$ is the Stefan-Boltzmann constant, $T_{\mathrm{s}}$ and $\mathrm{T}_{\mathrm{a}}$ are the surface and ambient air temperature, $h_{c}$ is the convection heat transfer coefficient, $k$ is thermal conductivity of the ground, $\lambda$ is the latent heat of vaporization and $E$ is the evaporation rate.

In equation 1, the first two terms on the left represent the absorbed solar shortwave radiation, the third term represents absorbed long wave radiation, and the final left hand term represents anthropogenic heat flux at the surface. The 
first term on the right represents emitted long wave radiation flux, the second term is convective flux, the third term represents conduction into the ground, and the final right hand term is the latent heat flux.

\subsubsection{Urban Heat Island Causes}

Human development, especially in high density urban areas, alters the earth's surface to the extent that the climate in urban areas has been influenced on the mesoscale ( 2 to $200 \mathrm{~km})$. It has been shown that urban areas are on average warmer than their surroundings, as depicted in Figure 1. This effect is known as the "Urban Heat Island" (UHI). UHI's are a result of the man-made changes to the urban surface, as well as heat produced by buildings, transportation and people [1]. While the UHI may be beneficial in cold heating dominated climates, it contributes to thermal discomfort and higher airconditioning loads in warmer climates. In almost all climates of the United States, building energy use is dominated by summertime cooling loads.

Throughout the course of a day, the heat island intensity changes, typically reaching a maximum at night ( $8 \mathrm{C}$ under ideal conditions). Prevailing weather conditions also impact heat island intensity with the strongest heat islands generally experienced during clear, calm conditions. Although heat island are often stronger in the winter - the impact of a summer heat island is typically more significant. In the city, the most intense nighttime heat island is seen near the surface, with decreasing intensity as elevation increases [1]. 


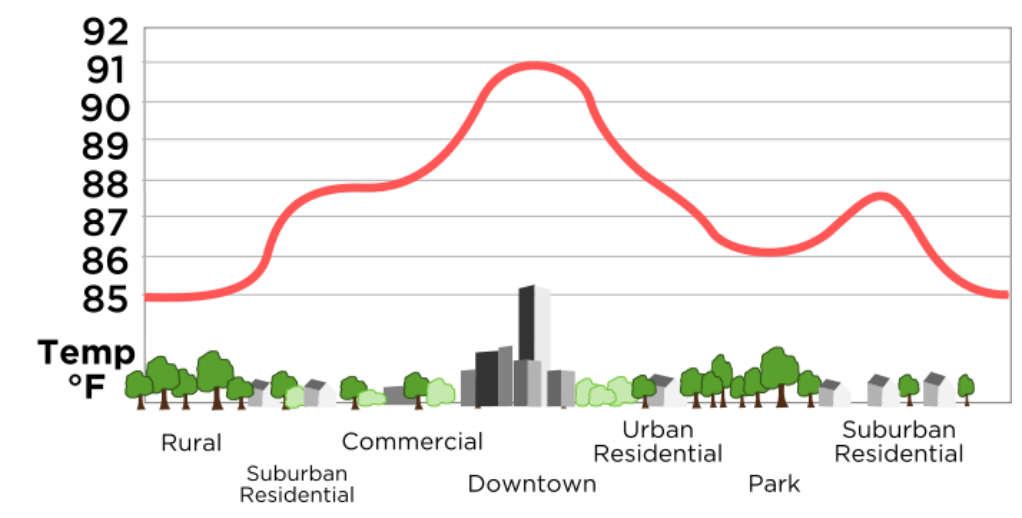

Figure 1: Typical urban heat island profile. (source: Wikimedia commons)

The $\mathrm{UHI}$ is caused by a number of factors which arise from differences in the energy balance of urban and rural areas as shown in Figure 2. Some factors contributing to $\mathrm{UHI}$ formation are [1]:

- Increased Thermal Mass - The presence of buildings, pavement and cement increases the thermal mass of urban areas relative to rural areas. These surfaces absorb and store heat, thereby increasing the thermal capacity of a city. Heat that is absorbed by buildings, roads and other impervious surface during the day is reemitted at night. This results in higher nighttime temperatures in urban versus rural environments.

- Urban Geometry - The geometry of cities often creates urban canyons that trap heat. As solar radiation is received by the city it cannot be easily reflected back into the sky without undergoing multiple reflections between building elements. The same geometry also traps heat by preventing long wave radiative cooling. Outgoing long wave radiation that would typically have a clear view of the sky is now obstructed by the walls of a canyon. 
This geometry reflects the outgoing radiation and ultimately traps additional heat.

Geometry also alters the wind flow within cities. The presence of buildings generally reduces wind speeds as compared to the unobstructed rural regions. Lower wind speeds reduce the amount of heat that is flushed from the city by the wind bringing in fresh rural air (advection).

- Anthropogenic Flux - The activities, energy consumption and metabolism of humans creates a heat source within the urban area. Vehicle emissions, building air conditioning systems, industrial activity, body heat, and other activities all contribute heat to the urban environment.

- Reduced Latent Heat Flux - Due to urban development, the amount of evaporative surface (such as forest and agricultural land) is significantly reduced. This means that more energy is put into sensible heat gain, as compared to an unaltered landscape where significant energy is stored as latent heat. The increased ratio of sensible to latent heat leads to an increase in air temperature.

- Decreased Albedo - Compared to natural surfaces, the albedo (or hemispherically and wavelength integrated reflectivity) of urban surfaces is significantly lower. The albedo of rooftops is particularly important due to the high surface area of roofs, as well as their location within the city. Due to their relatively clear view of the sky, roofs receive a greater proportion 
of the incoming solar radiation than streets, walls and other urban

surfaces.

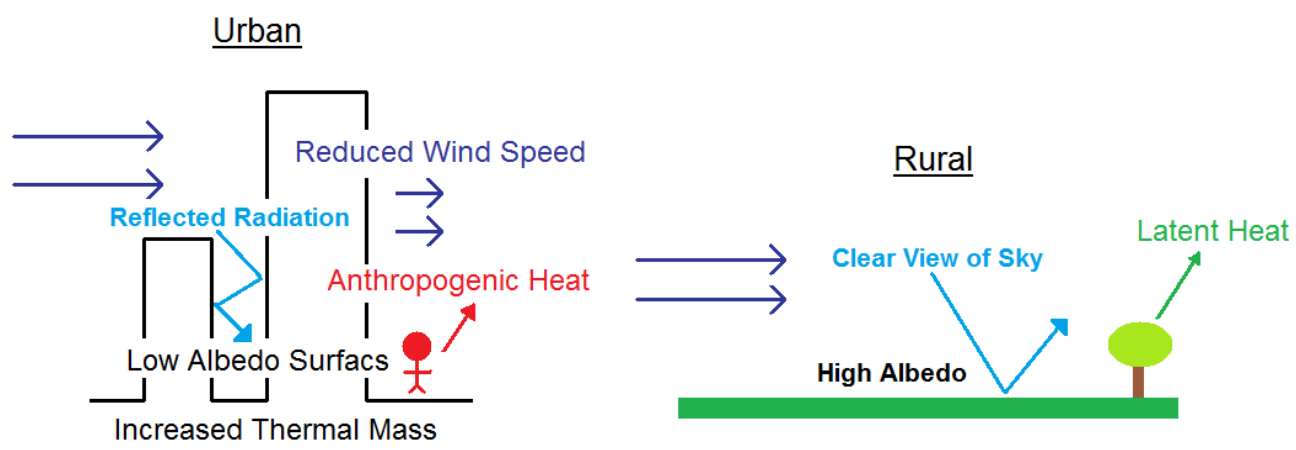

Figure 2: Comparison between the urban and rural surface energy balance. 


\subsection{Urban Heat Island Consequences}

The most direct effect of an Urban Heat Island is increased air temperatures in urban areas. Increased urban air temperatures result in a number of consequences, including:

- Energy Consumption - Increased urban air temperatures causes an increase in the energy used to cool buildings. Although there is a slight $\mathrm{UHI}$ benefit in the winter, this benefit is generally small compared to the penalty incurred during the cooling season. One method of analyzing the possible UHI impact is to consider the change in heating degree days and cooling degree days between climatically similar urban and rural areas. As presented in table 1, it can be seen that urban areas have fewer heating degree days, but more cooling degree days, than their rural counterparts.

One study reports annual energy savings due to UHI mitigation for Chicago and Houston of 65 GWh and 236 GWh respectively. Peak power reductions are estimated at $33 \mathrm{MW}$ and $218 \mathrm{MW}$. These savings only consider the energy saved through reductions in air temperature. There are also significant savings due to the direct impact of reflective roofs and shade trees on the heat gain of buildings. If all of these factors are considered, the energy savings for Chicago and Houston is estimated at 253 GWh and 1,181 GWh respectively [2].

- Heat Related IIIness \& Death - As temperatures in the city increase, so does the likelihood of heat related illness. In a 2006 report, the Center for 
Disease Control reported an annual average of 688 deaths resulting from exposure to extreme heat [3]. Exposure to extreme and prolonged heat is associated with cramps, fainting, heat exhaustion and heatstroke, with heatstroke being most common cause of heat related death. Regardless of the cause, heat mortality tends to occur 1 or 2 days after the peak temperature of a heat wave. The increased thermal storage of cities, which leads to increased overnight temperatures, can deprive the urban dweller of nighttime relief and exacerbate heat related health problems [4].

- Poor Air Quality - Mitigation of the UHI will not only save significant energy, but may also improve urban air quality. Decreased urban air temperatures can result in a decrease in some photochemical reaction rates, and decreased hydrocarbon (and other) emissions. All of these factors yield a decrease in the potential for poor air quality. An early study showed that albedo alteration can reduce the population weighted exceedence exposure to ozone by up to $16 \%$ during peak afternoon hours [5]. In a more recent modeling effort, results indicate the potential to decrease ozone levels in Sacramento, CA by $5-11 \mathrm{ppb}$. The daily 8 hour maximum can be decreased by $4-13 \%$ [6].

- Economic Impact - All of the above UHI consequences also have an economic impact. The societal cost of smog and increased demand for healthcare should certainly be considered, but is also hard to calculate. Fortunately, the cost of increased energy consumption is slightly easier to 
quantify. One study estimates the savings potential of UHI mitigation strategies. In Chicago and Houston, the savings due to decreases in air temperature are estimated at 5.4 million and 15.6 million dollars respectively. If the direct impact of UHI mitigation strategies is considered, these savings increase to 29.8 and 81.8 million dollars respectively [2].

Table 1: Change in heating degree days (HDD) and cooling degree days (CDD) due to the UHI. Adapted from [5].

\begin{tabular}{lcc}
\hline Location & HDD $\Delta \%$ & CDD $\Delta \%$ \\
\hline Los Angeles & -32 & +92 \\
Washington DC & -6 & +21 \\
New York & -7 & +24 \\
Seattle & -13 & +54 \\
Chicago & -7 & +24
\end{tabular}

\subsection{Urban Heat Island Mitigation}

UHI mitigation techniques have focused on altering the urban energy balance to return it to a more natural state. Researchers have considered a variety of UHI mitigation techniques, with a lot of focus placed on understanding the impact of albedo alteration of urban surfaces, particularly roofs. Unlike many mitigation techniques which must be addressed through changes in urban planning, the characteristics of building roofs can be changed with relative ease. Buildings are typically re-roofed every $15-20$ years, which provides an opportunity to consider different roofing materials with various thermal properties. Table 2 outlines some commonly chosen roofing technologies. Further discussion and reference to previous studies is provided below. 
Table 2: Comparison of various roof types.

\begin{tabular}{ccc}
\hline Reported Benefits & $\begin{array}{c}\text { Incentives for } \\
\text { Adoption }\end{array}$ \\
\hline Black Roof & Low Albedo --> High Temp & $\begin{array}{c}\text { Status Quo } \\
\text { Aesthetics/low glare }\end{array}$ \\
\hline White Roof & High Albedo --> Low Temp & $\begin{array}{c}\text { LEED Credits } \\
\text { Building Codes }\end{array}$ \\
\hline Green Roof & $\begin{array}{c}\text { Evapotranspiration, Shading, } \\
\text { Insulation --> Low Temp }\end{array}$ & $\begin{array}{c}\text { LEED Credits } \\
\text { Local, State, }\end{array}$ \\
\hline $\begin{array}{c}\text { Photovoltaic } \\
\text { Roof }\end{array}$ & Stormwater retention & Federal Tax Credits \\
\hline
\end{tabular}

\subsubsection{Cool Roofs (White Roofs)}

For several decades now research has been conducted into the use of cool roof (high solar reflective or high albedo) technologies both for building energy savings and urban heat island mitigation. Measurements in various climates have shown that white roofs can reduce rooftop temperatures $20-42^{\circ} \mathrm{C}$ as compared to dark roofs [7-9]. In one of the early studies of cool roofing, researchers used building energy simulation of prototypical buildings across 11 US metropolitan areas to evaluate the potential energy savings of highly reflective roofing [10]. In extrapolating their results to the entire US, Akbari estimated that replacing dark roofs with white roofs has the potential to save up to $10 \mathrm{TWh}$ (1E14 Wh) per year (circa 1999). According to the US Energy Information Administration, electricity sales in 1999 were $1.14 \mathrm{E} 15 \mathrm{Wh}$ and 
1.0E15 Wh in the residential and commercial buildings sectors, respectively [11]. So, the savings potential reported by Akbari amounts to about $0.5 \%$ of all building electricity use. Another building energy simulation study [12] found that a white roof with a summertime mid-day surface temperature reduction of $8^{\circ} \mathrm{C}$ produced an annual energy savings of approximately $3 \%$.

The few studies that have explored urban climate impacts of roof albedo have generally done so using coarse resolution mesoscale models that do not represent the morphology of the city or the thermal characteristics of insulated roofing (e.g. [13-15]). Despite their limitations such modeling efforts do provide a quantitative assessment of potential for reducing urban air temperatures. For example, [13] found that increasing the average albedo of Los Angeles California by 0.14 would reduce summertime peak daytime air temperatures by as much as $1.5^{\circ} \mathrm{C}$.

\subsubsection{Green Roofs}

In recent years there has been an increased interest in use of vegetated green roofs (also referred to as ecoroofs) to provide a variety of ecosystem services (e.g., [16-21]). Research suggests that green roofs can aid in stormwater retention, reduce building energy loads, mitigate the urban heat island effect and increase the lifespan of a roof [22]. In response to the reported benefits of green roofs, cities such as Portland, Oregon and Toronto, Canada are beginning to offer incentives, or even mandates, for green roof installation [23, 24]. Many studies have investigated the impact of green roofs on building surface 
temperatures, heat fluxes into the building, and building energy use [25-27]. Few studies, however, have tried to quantify the urban climate impacts of green roofs. One such study, [28], used a microscale model to estimate the temperature reduction potential of green walls and roofs in nine cities around the world. While this study was physically-based, representing the key physical properties and processes, it had several limitations. The model framework and canyon geometries investigated were two-dimensional, buoyancy effects were not considered, and the buildings were modeled as solid blocks of concrete with no windows, and more importantly, no insulation - thus overestimating thermal storage in the building envelope. The study also lacked comparison and validation with observations.

Some studies have also considered the micro-climate impact of increasing vegetation in urban areas. For example, [13] found that a $7 \%$ increase in the vegetation cover of all developed land use types in the Los Angeles basin resulted in a maximum air temperature reduction of $1.3^{\circ} \mathrm{C}$. It should be noted that this study modeled a general increase in vegetation cover, and did not specifically consider green roofs.

\subsubsection{Rooftop Integrated Photovoltaics}

Another trend in sustainable building technologies is the use of rooftops for the generation of electric energy. While this sometimes involves wind power, most applications involve the collection of solar energy. In recent years, installation of building integrated photovoltaic (PV) solar panels has increased 
dramatically [29]. Between 2007 and 2008 the installed PV capacity in the United States increased by $63 \%$, with projections for even greater future growth.

Rooftop mounted systems accounted for $74 \%$ of the installed PV generation capacity in the US during 2008. This increased adoption of PV technology can be attributed to the decreasing cost of PV modules, increasing module efficiency, and incentives provided by utilities, states and federal government. Additionally, there is growing interest in moving towards renewable energy sources to garner credits from building rating systems such as the US Green Building Council's LEED program.

These sustainable roofing trends are leading to changes in urban rooftop environments that may impact the urban climate. As more research on the benefits of these systems is conducted, cities may become motivated to increase incentives or establish mandates for such technology. This change has the potential to result in widespread alteration of urban surfaces. Such changes to the built environment should, therefore, be looked at from the perspective of implications for the urban atmospheric environment. Furthermore, it is important to explore comparative advantages of one technology over another and the potential for technologies to be combined in a synergistic way.

\subsection{Rooftop Surface Energy Balance}

The energy balances of traditional and photovoltaic roofs are shown in Figures 3 and 4 . The goal of the present study is to evaluate the sensible flux terms for each roof type in order to provide a measure of the contribution of each 
roof type to the urban heat island. For the conventional roof this entails estimation of just the sensible flux from the horizontal roof surface. For the photovoltaic roof there are three individual sensible fluxes to be evaluated- one from the roof surface, and one from each side of the photovoltaic panel. The remaining energy balance terms influence the roof surface temperature, thereby influencing the magnitude of the sensible flux term.

When analyzing the Urban Heat Island impact of different roof treatments for a given day of the year, it is meaningful to consider the peak sensible flux $\left(\mathrm{W} / \mathrm{m}^{2}\right)$, as well as the total daily flux $(\mathrm{W}-\mathrm{h} / \mathrm{m} 2)$. The peak flux will impact daytime maximum temperature, which in turn impacts air conditioning energy demand, heat related mortality, urban air quality, and peak electric loads. On the other hand, total daily flux will influence nighttime cooling of a city, which also plays a role in energy use, heat related mortality and perpetuation of a UHI cycle. In fact, the UHI intensity generally reaches a peak in early morning hours [1]. If only the roof's peak surface temperature or peak flux were considered, the impact on a nighttime heat island is not accounted for. 


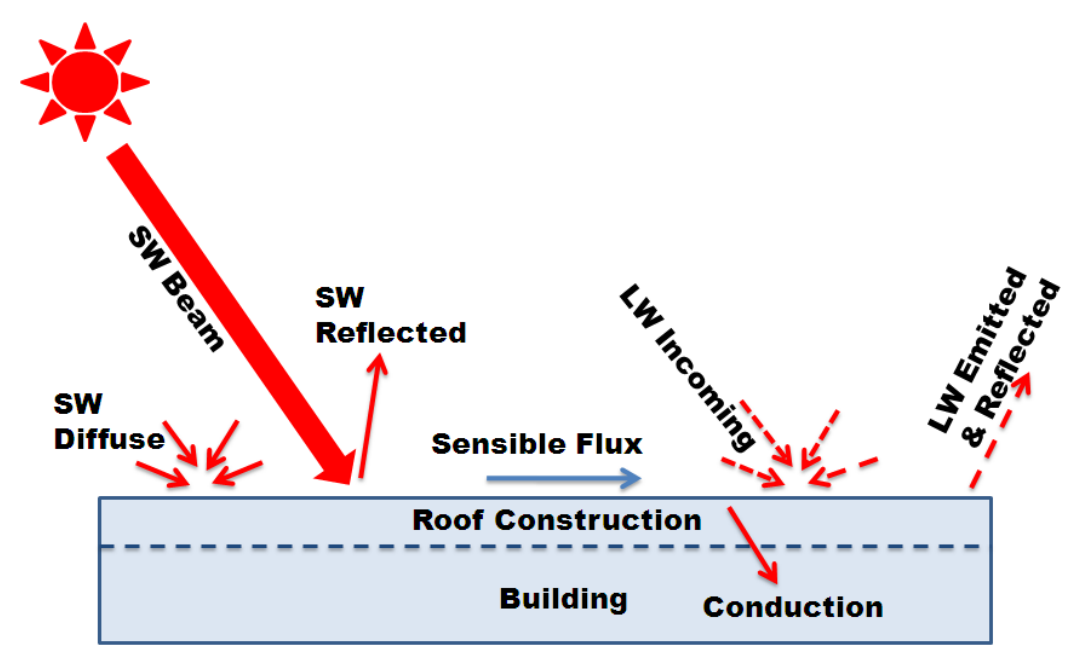

Figure 3: Surface energy balance for an unshaded roof

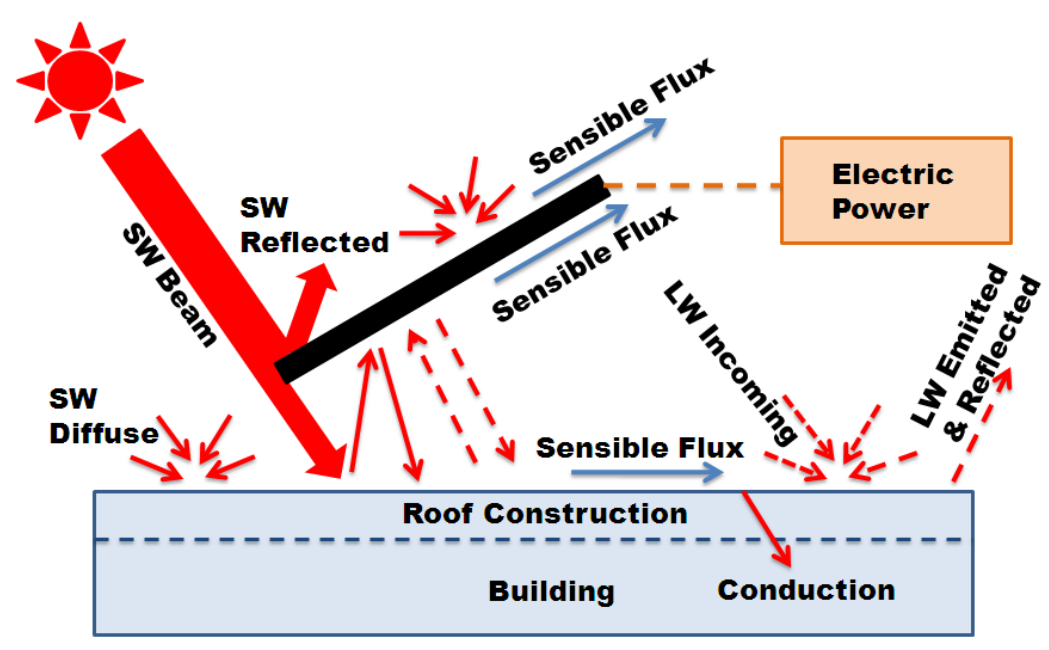

Figure 4: Surface energy balance for a shaded roof

\section{Overview of this Study}

The goal of this study is to compare the heat island impact of various commercial building roof treatments. Black and white membrane roofs, as well as vegetated green roofs are compared in two configurations: (1), traditional installation with no shading and (2), installation with a photovoltaic solar array 
partially shading the roof. This set of tests, along with the naming convention used in the remainder of this paper, is given in Figure 5.

\begin{tabular}{|c|c|c|}
\hline Roof Type & Unshaded & Shaded by PV \\
\hline Black Membrane & Black & Black PV \\
\hline White Membrane & White & White PV \\
\hline Green (vegetated) & Green & Green PV \\
\hline
\end{tabular}

Figure 5: Test matrix of roof types studied with naming convention defined for each roof type combination.

In order to generalize this study to various climates, a sequence of modeling techniques was used. First, a building energy model (EnergyPlus) was adapted for use in this study and validated against field measurements. This modeling framework is used to simulate each roof configuration on prototypical commercial office buildings in six cities. Results are then used to calculate the sensible heat flux from each roof type to the urban atmosphere.

To gain a reasonable understanding of how the sensible flux resulting from each roof choice impacts urban air temperatures, a second modeling framework was required. The fluxes calculated using building energy modeling were used as inputs to a mesoscale meteorological model (MM5). The mesoscale model allows for analysis of how the changes in urban flux interact with the urban microclimate and the larger meteorological system surrounding a city. Figure 6 illustrates the coupling between these two modeling systems. 


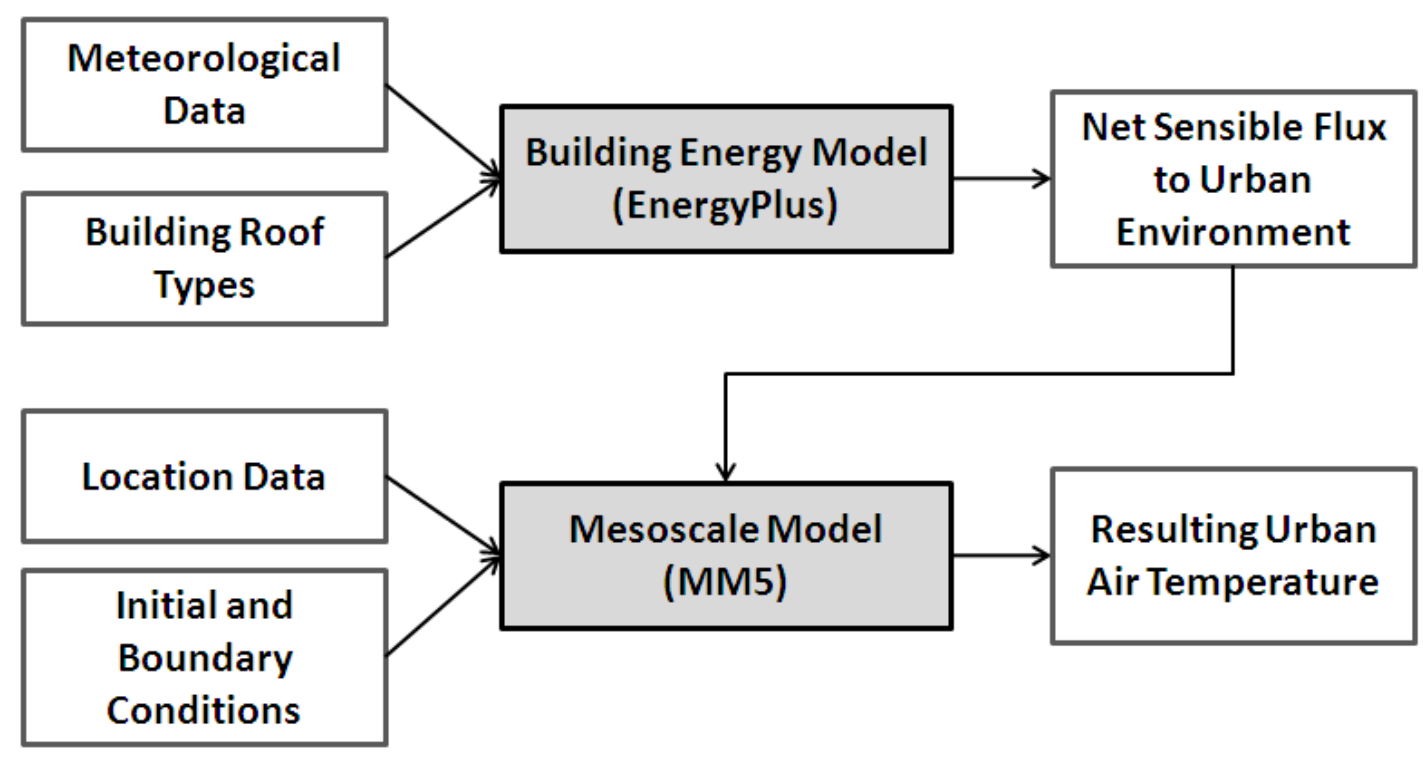

Figure 6: Coupling of building energy and mesoscale models

\section{EnergyPlus Modeling Methods}

A brief overview of the EnergyPlus building energy simulation software is provided in section 3.1. Section 3.2 then presents the process for calculating surface temperatures and sensible flux of unshaded roofs. This is followed in section 3.3 by a description of the methods used for modeling a roof with partial shading due to PV panels. Validation of both models is then presented in section 4.

\subsection{EnergyPlus Software Overview}

EnergyPlus is a widely accepted simulation program for modeling annual building energy consumption. Released in 2001, EnergyPlus replaced its 
predecessors, BLAST and DOE-2, which had some technical and structural limitations (Crawley et al. 2004). A typical EnergyPlus simulation uses 6 to 15 time steps per hour to represent building operation subject to the weather of a typical meteorological year. As of its April 2007 release, Energyplus includes a module for simulating the energy balance of a vegetated roof [30]. EnergyPlus is commonly used to model heating, cooling, lighting, ventilation, and other energy flows within buildings - but this same calculation engine can also be used to model the energy flow between a building and the urban environment. In this research, Energyplus is used as the primary means of calculating the rooftop surface energy balance and the associated rooftop surface temperature and convection coefficients. Figure 7 illustrates the basic modular structure internal to EnergyPlus. In order to run an EnergyPlus simulation, two input files are required: a building input file, and a weather data file. Using this building and weather information, the Surface Heat Balance Manger calculates surface temperatures for all interior and exterior building surfaces.

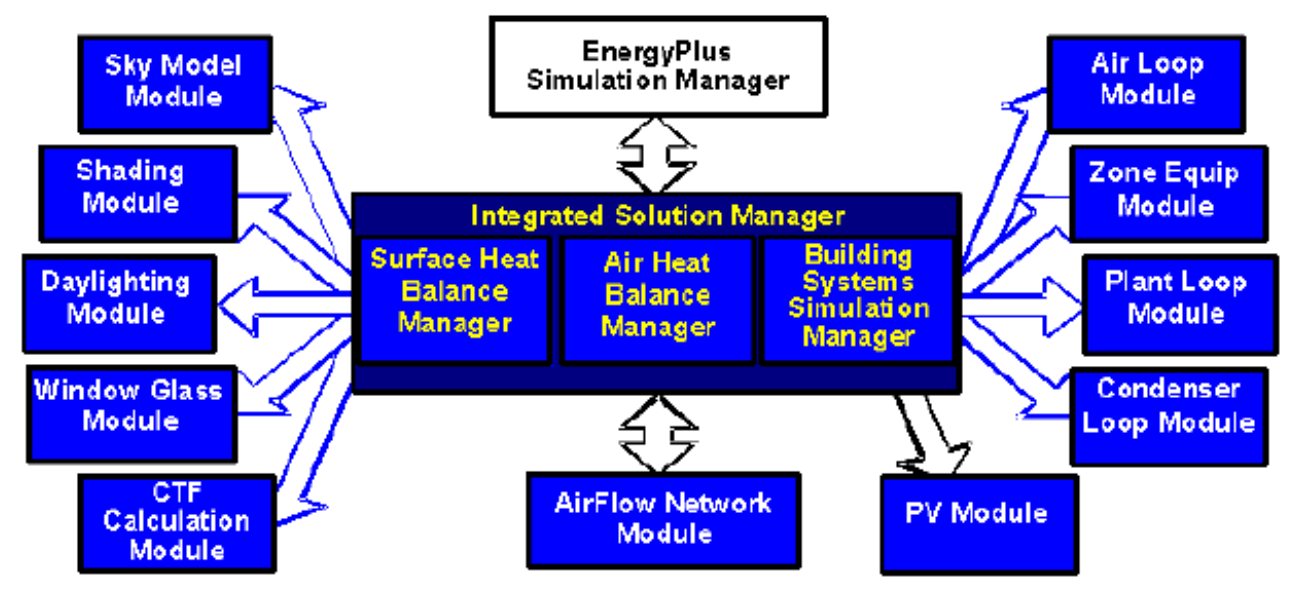

Figure 7: Schematic overview of EnergyPlus simulation modules. 


\subsubsection{EnergyPlus Building Input File:}

The Input Data File (IDF) describes all aspects of a building, except the climate in which it is located. This includes building geometry, construction materials, glazing characteristics, internal loads, mechanical equipment, HVAC operations, and human occupancy schedules. For this analysis, IDF files were taken from a database of US Department of Energy (DOE) benchmark buildings that represent typical new construction for buildings in different climate zones [31]. The DOE benchmark files were subsequently modified to create models for the six different roof types of interest. This included black, white, and green roofs individually and also shaded by photovoltaic (PV) panels. The roof types which included PV panels are hereafter referred to as black-PV, white-PV, and green$\mathrm{PV}$, to reflect both the underlying characteristics of the base roof and the presence of the PV panels.

\subsubsection{EnergyPlus Weather Data Input File:}

EnergyPlus uses an annual weather data file, which is generally derived from Typical Meteorological Year (TMY) weather data. These weather data provide hourly values of direct radiation, diffuse radiation, dry bulb temperature, dew point, relative humidity, and wind speed for a 1-year period. The datasets represent typical conditions at a given location based on long term (usually 30 year) meteorological observations. [32]. 
In order to investigate regional climate-driven differences in roof performance, six cities were chosen for analysis. Climate zone boundaries defined in the ASHRAE building standard [33] were chosen, with analysis conducted on buildings located in climate zones 2 through 6 . As can be seen in Figure 8, these climate zones represent most of the contiguous United States. Climate zones 7 and 8 are generally very cold, and concern for Urban Heat Islands in these climates is minimal.

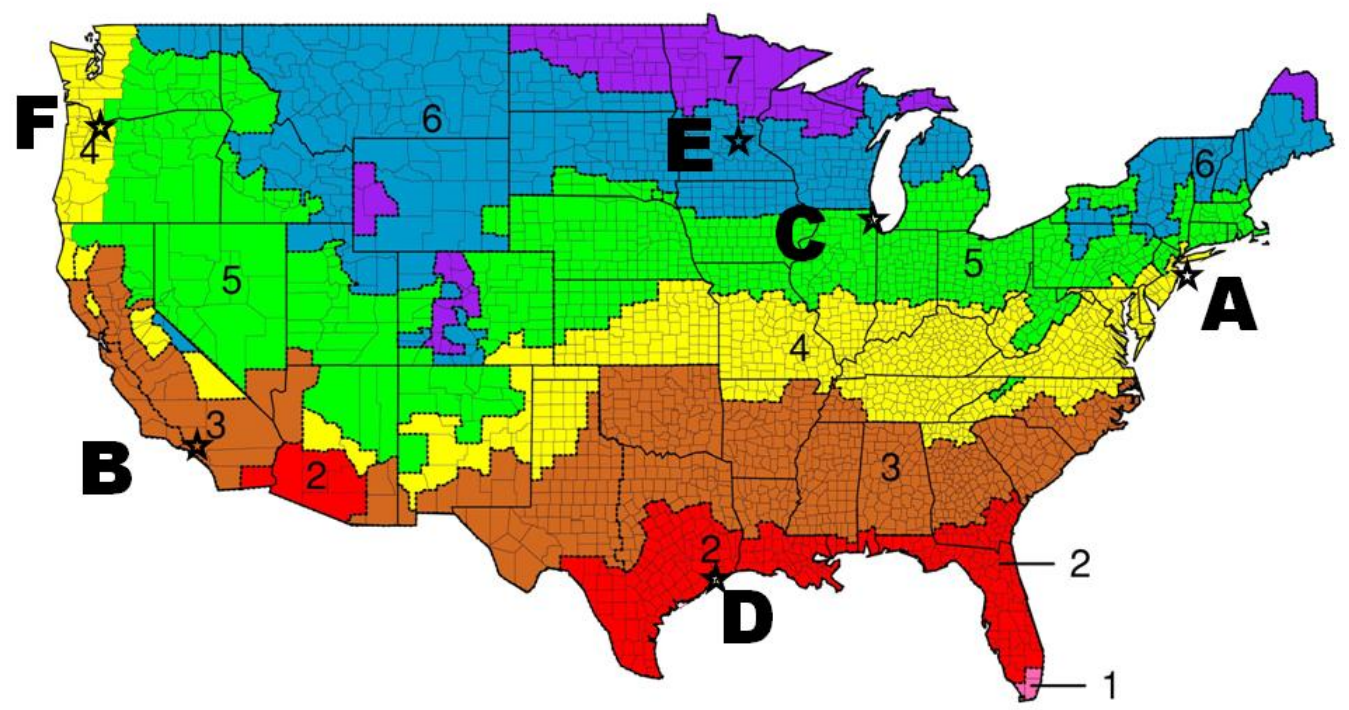

Figure 8: Map of U.S. climate zones. Cities analyzed are: A-New York, B-Los Angeles, C-Chicago, D-Houston, E-Minneapolis, and F-Portland. Source: [33].

Cities chosen for analysis are shown in Table 3. Based on US Census data the largest city in each climate zone was chosen for analysis. In addition, Portland, OR was selected due to the fact that observational validation data were available in this city. For the cities of New York and Portland, DOE benchmark building models were not available. In these instances, models for the nearby 
cities of Baltimore and Seattle were chosen as surrogates. This substitution is considered acceptable as building energy standards (e.g. ASHRAE 90.1 and IECC) generally have consistent construction specifications within any individual climate zone.

Weather data files were chosen from the available EnergyPlus datasets. Care was taken to select weather file data from the station closest to the city center. For cities in California it is common to substitute TMY data with representative weather data from a collection of California Climate Zone (CCZ) datasets (available from the US DoE). For Los Angeles this CCZ dataset was used to provide a better representation of the climate expected within the metro region. Table 3 documents the weather files and benchmark buildings used for each city's analysis.

Table 3: Cities chosen for EnergyPlus analysis

\begin{tabular}{|c|c|c|c|c|c|}
\hline City & $\begin{array}{c}\text { Population } \\
\text { (million) }\end{array}$ & $\begin{array}{c}\text { Climate } \\
\text { Zone }\end{array}$ & $\begin{array}{c}\text { Cooling } \\
\text { Degree Days } \\
\text { (base 65) }\end{array}$ & $\begin{array}{l}\text { Benchmark } \\
\text { Building } \\
\text { Used }\end{array}$ & $\begin{array}{c}\text { Weather File } \\
\text { Used }\end{array}$ \\
\hline $\begin{array}{c}\text { New York, } \\
\text { NY }\end{array}$ & 8.4 & 4 & 1090 & Baltimore & $\begin{array}{l}\text { New York - } \\
\text { Central Park }\end{array}$ \\
\hline $\begin{array}{c}\text { Los Angeles, } \\
\text { CA }\end{array}$ & 3.8 & 3 & 617 & Los Angeles & $\begin{array}{c}\text { California } \\
\text { Climate Zone } \\
9\end{array}$ \\
\hline Chicago, IL & 2.8 & 5 & 1022 & Chicago & $\begin{array}{c}\text { Chicago- } \\
\text { Midway } \\
\text { Airport }\end{array}$ \\
\hline Houston, TX & 2.3 & 2 & 3100 & Houston & $\begin{array}{c}\text { Houston- } \\
\text { Hobby Airport }\end{array}$ \\
\hline $\begin{array}{l}\text { Minneapolis/ } \\
\text { St. Paul, Mn }\end{array}$ & 0.7 & 6 & 750 & Minneapolis & $\begin{array}{l}\text { Minneapolis } \\
\text { St. Paul Int'l } \\
\text { Airport }\end{array}$ \\
\hline Portland, OR & 0.6 & 4 & 423 & Seattle & $\begin{array}{c}\text { Portland Int'l } \\
\text { Airport }\end{array}$ \\
\hline
\end{tabular}




\subsubsection{EnergyPlus Surface Heat Balance Algorithm}

Central to the rooftop energy balance used in this study is the "Surface Heat Balance Manager" component of EnergyPlus. This EnergyPlus module computes heat fluxes at building surfaces based on indoor and outdoor environmental conditions. The heat balance at the outside surface of a building is given by:

$$
q_{\text {asol }}+q_{L W R}+q_{\text {conv }}-q_{k o}=0
$$

where $\mathrm{q}_{\text {asol }}$ is the absorbed short wave solar radiation flux, $\mathrm{q}_{\mathrm{LWR}}$ is the net long wave radiation flux exchange, $q_{\text {conv }}$ is the convective flux, and $\mathrm{q}^{\prime \prime}{ }_{\mathrm{o}}$ is the conduction heat flux into the wall. Conduction is calculated using the "Conduction Transfer Function" (CTF) method. The CTF method uses material properties to calculate conduction transfer functions, which are used to calculate the conduction flux based on temperature and flux histories. The convection model used is based on the DOE-2 algorithm, which accounts for natural and forced convection, as well as surface orientation. Key input parameters are: local wind speed, tilt angle, surface temperature, ambient temperature, and roughness coefficients. The convective flux is then given by

$$
q_{\text {conv }}=h_{c}{ }^{*}\left(T_{\text {surface }}-T_{\text {ambient }}\right)
$$

where $h_{c}$ is defined by:

$$
h_{c}=h_{n}+R_{f}\left(h_{c, \text { glass }}-h_{n}\right) .
$$




$$
h_{c, \text { glass }}=\sqrt{h_{n}^{2}+\left(a * V^{b}\right)^{2}}
$$

Here, $a, b$ and $R_{f}$ are surface roughness coefficients, and $V$ is the local wind speed. For an upward facing surface that is hotter than the ambient air the natural convection component is given by:

$$
h_{n}=\frac{9.482 *|\Delta T|^{1 / 3}}{7.283-|\cos (\Sigma)|}
$$

For a downward facing surface it is given by:

$$
h_{n}=\frac{1.810 *|\Delta T|^{1 / 3}}{1.382+|\cos (\Sigma)|}
$$

In these expressions $\Sigma$ is the glazing tilt angle, and $\Delta \mathrm{T}$ is the temperature difference between the glazing surface and the ambient air.

\subsubsection{Site Weather Correction for Building Models}

In most cases, EnergyPlus derives its climate information directly from the weather input data file. A few corrections are required however (see [34] for detailed explanation of the following). Temperature and wind speed are corrected to adjust for the difference between the building and weather station height above ground. Temperature corrections assume a weather station height of 1.5 $\mathrm{m}$, and adjustments are made based on the US Standard Atmosphere model. Wind speed corrections use a default weather station height of $10 \mathrm{~m}$, and corrections are made based on an ASHRAE correction equation. Corrections also account for urban boundary layer effects and characteristic surface roughness of the surrounding urban topography. EnergyPlus defaults were used for both corrections. 


\subsubsection{EnergyPlus Green Roof Module}

In this study, the EnergyPlus green roof module [30] is used to model green roof fluxes. In this model the green roof soil and foliage energy balance is calculated following the "Fast All Season Soil Strength model (FASST). The following energy balance is used to calculate $F_{f}$, net flux to the foliage layer:

$$
F_{f}=\sigma_{f}\left[I_{S W}\left(1-\alpha_{f}\right)+\varepsilon_{f} I_{L W}-\varepsilon_{f} \sigma T_{f}^{4}\right]+\frac{\sigma_{f} \varepsilon_{g} \varepsilon_{f} \sigma}{\varepsilon_{1}}\left(T_{g}^{4}-T_{f}^{4}\right)+H_{f}+L_{f}
$$

The first three terms account for short-wave absorption, long-wave absorption and long-wave emitted energy. The next term accounts for long wave exchange between the plant canopy and ground surface. The final two terms, $\mathrm{H}_{f}$ and $\mathrm{L}_{f}$ account for sensible and latent fluxes respectively. Of particular interest in this study is $\mathrm{H}_{\mathrm{f}}$, given by:

$$
H_{f}=\left(1.1 L A I \rho_{a f} C_{p, a} C_{f} W_{a f}\right)\left(T_{a f}-T_{f}\right)
$$

Where:

$$
\begin{aligned}
& \text { LAI = Leaf Area Index (a measure of leaf density) } \\
& \rho_{a f}=\text { Density of air at foliage temperature } \\
& C_{p, a}=\text { Specific heat of air at constant pressure } \\
& C_{f}=\text { Bulk heat transfer coefficient given by a function of wind speed, } \\
& \text { foliage fraction and geometric length scales } \\
& W_{a f}=\text { Wind speed within canopy }
\end{aligned}
$$




$$
T_{a f}-T_{f}=\text { Air temperature within canopy }- \text { Foliage temperature }
$$

The soil surface energy balance is similar to the foliage case, with the addition of a conduction term:

$$
F_{g}=\left(1-\sigma_{f}\right)\left[I_{S W}\left(1-\alpha_{g}\right)+\varepsilon_{g} I_{L W}-\varepsilon_{g} \sigma T_{g}^{4}\right]-\frac{\sigma_{f} \varepsilon_{g} \varepsilon_{f} \sigma}{\varepsilon_{1}}\left(T_{g}^{4}-T_{f}^{4}\right)+H_{g}+L_{g}+K \frac{\partial T_{g}}{\partial Z}
$$

In this case, the first three terms account for absorbed short-wave, absorbed long wave and emitted long wave energy. The fourth term accounts for long-wave exchange between the plant canopy and soil. $H_{g}$ and $L_{g}$ are sensible and latent fluxes between the ground and surrounding air, and the final term accounts for conduction and storage in the soil layer. In the soil, $\mathrm{Hg}$ is calculated by:

$$
H_{g}=\left(\rho_{a g} C_{p, a} C_{h g} W_{a f}\right)\left(T_{a f}-T_{g}\right)
$$

Where the new terms are:

$$
\begin{aligned}
& \rho_{a g}=\text { Density of air at soil temperature } \\
& C_{h g}=\text { Sensible flux bulk transfer coefficient at ground layer } \\
& T_{g}=\text { Ground temperature }
\end{aligned}
$$

In this case the bulk transfer coefficient, $\mathrm{C}_{\mathrm{hg}}$, is given by a function of the bulk transfer coefficient near ground, as well as the bulk transfer coefficient near the foliage-atmosphere interface. This function depends on ground and foliage roughness lengths, the bulk Richardson number, and hence the wind speed. The interested reader is referred to [30] for the complete set of equations implemented by EnergyPlus in the green roof module. 


\subsubsection{Chosen parameters for green roof modeling}

Default values were used for all green roof parameters. Some key green roof parameter values are: height of plants $(0.2 \mathrm{~m})$; leaf area index (1.0); and soil thickness $(0.15 \mathrm{~m})$. The roof irrigation feature in EnergyPlus was also implemented with a 'smart schedule' which activates an early morning irrigation system if the soil volumetric moisture content falls below $\left(0.15 \mathrm{~m}^{3} / \mathrm{m}^{3}\right)$.

For the present analysis, the EnergyPlus green roof module was used to output: soil surface temperature, soil sensible heat flux and plant canopy sensible heat flux. These variables are not normally available for output, so a custom version of EnergyPlus with additional green roof output capability was created. The total green roof sensible flux is the sum of the sensible fluxes from the soil and plant canopy. For details on the calculation of these terms, refer to [30].

\subsection{Traditional Roof Model (unshaded)}

Black, white and green roofs were modeled using EnergyPlus V5.0. The building geometry and weather input files described in section 2.1 were used for their respective cities. Membrane material properties chosen for analysis were selected from the Lawrence Berkeley National Laboratory "Cool Roofing Materials Database". Annual simulations were conducted for black and white EPDM membranes with solar reflectances of 0.06 for the black membrane and 0.69 for the white one. The corresponding infrared emissivities were 0.86 and $0.87[35]$. 


\subsubsection{Surface Convection and Heat Flux to Urban Environment}

Figure 9 outlines the process of calculating convective heat flux per unit area of roof. The heat transfer coefficient for the roof surface is calculated using the DOE-2 convection algorithm at each time step of the EnergyPlus simulation (see section 3.1). The sensible flux per unit area of roof is simply given by eqn. (3).

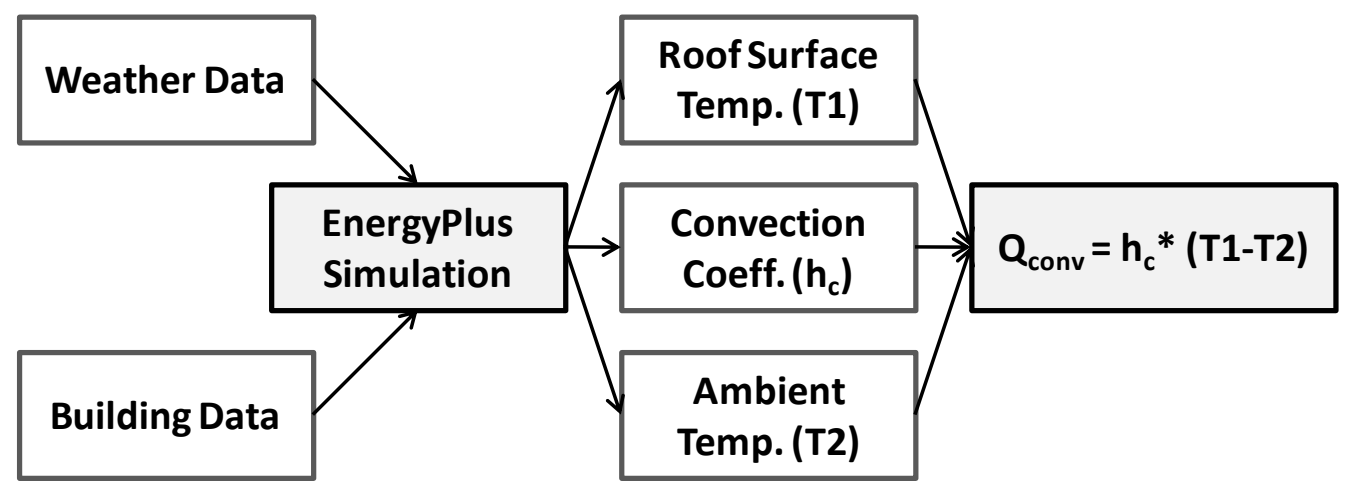

Figure 9: Calculation procedure for sensible heat fluxes on a traditional roof

\subsection{Photovoltaic Roof Model (partially shaded)}

The methodology used to model a partially shaded roof originates with an analysis of the surface energy balance for a PV roof. When PV panels are present, a portion of the roof is shaded from short wave beam radiation. Additionally, a portion of the roof is now receiving additional long wave radiation from the PV panel.

While EnergyPlus allows modeling of shading devices, a shortcoming of the model is that it only considers the decrease in short wave irradiance. In the 
case of a relatively hot $\mathrm{PV}$ panel shading a roof, there is a long wave radiation term that must be accounted for. To address this shortcoming of EnergyPlus, an alternative method of modeling the PV shading was developed. This method relies of adjustments to the effective sky view factor for both long and short wave radiation, as well as a modification to the sky temperature so that it matches the predicted surface temperature of a PV panel. Figure 10 shows the general calculation procedure used to model the convection from the shaded portion of a roof.

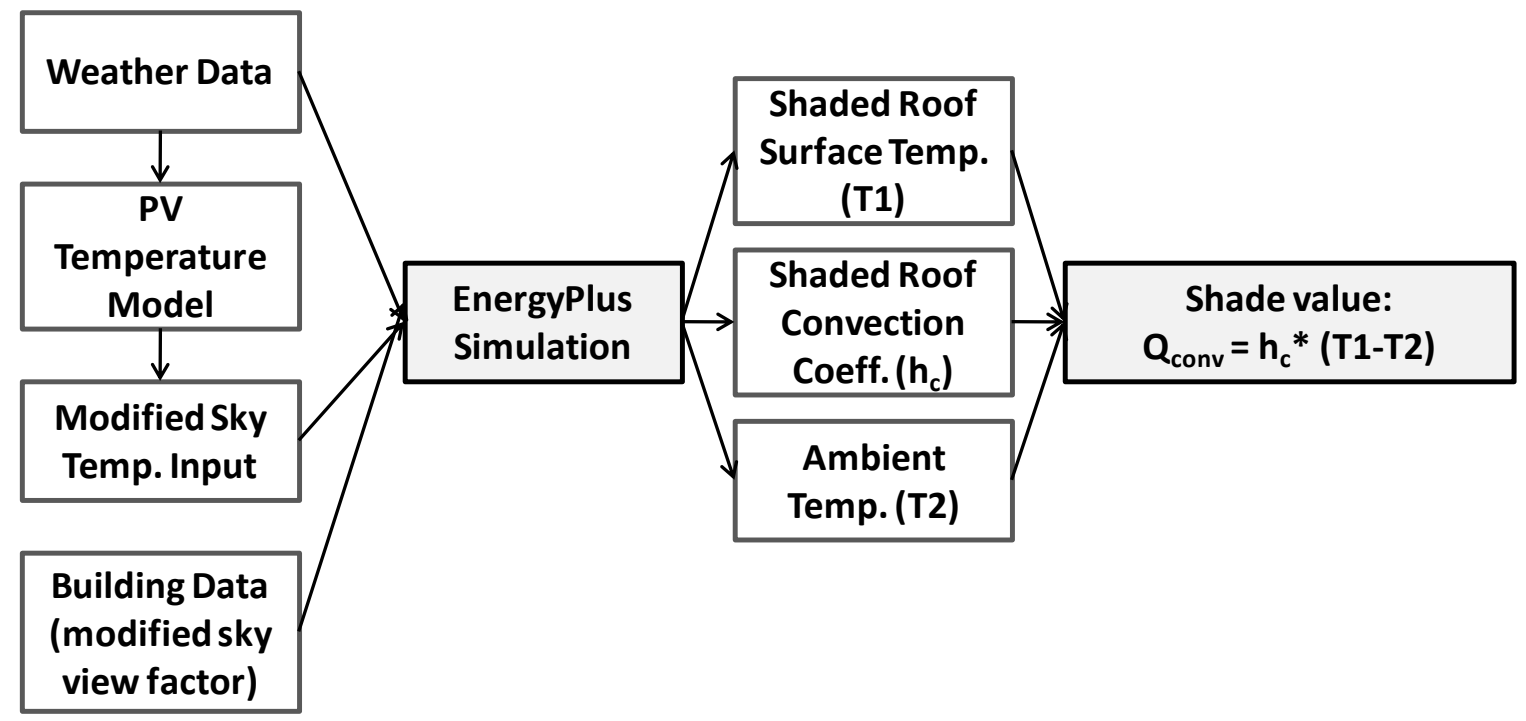

Figure 10: Calculation procedure for flux calculations for the PV-shaded portion of a roof

\subsubsection{PV Roof Geometry}

For this analysis assumptions had to be made about what constitutes a typical rooftop PV installation. The roof is assumed to be covered with PV panels at a tilt angle, $\Sigma$ of 20 degrees, with each row extending the entire length of the 
roof in the east-west direction. In the North-South direction, rows are spaced at a distance of $L^{*} \operatorname{Cos}(\Sigma)$ where $L$ is the panel length (Figure 11). This spacing and tilt angle generally provide a good compromise between power production per panel, and total power production of the rooftop system. If a lower tilt angle were chosen, more panels could be installed without excessive self-shading (one panel row shading the next row at low solar angles); however, each panel would operate at a lower effective efficiency.

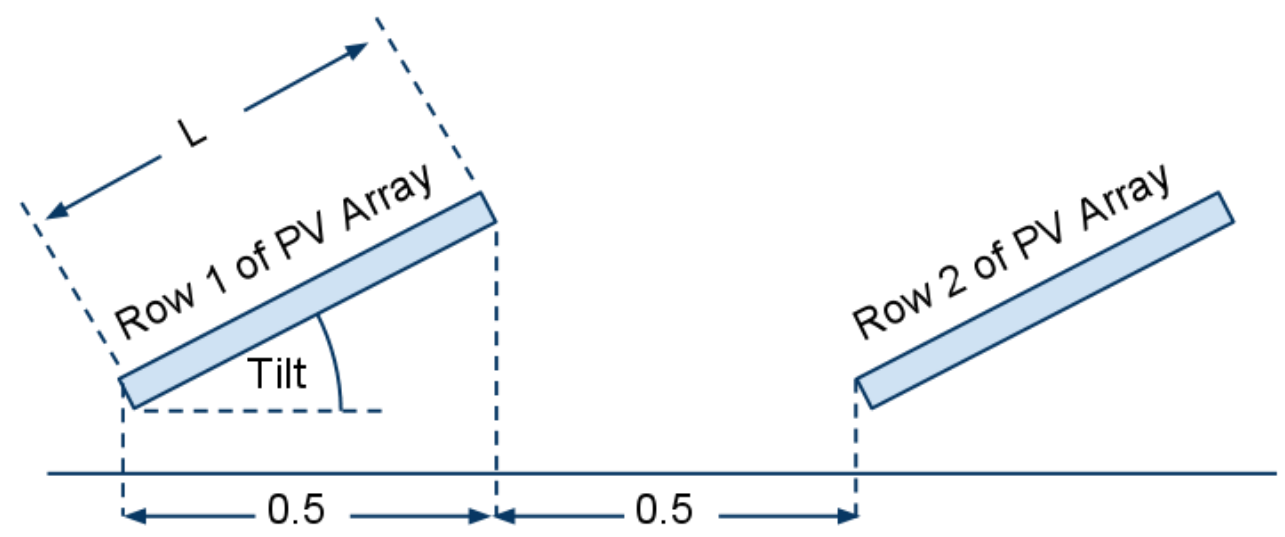

Figure 11: Geometry of rooftop PV array.

\subsubsection{PV Surface Temperature Model}

Surface temperature of each PV module is modeled using a series of empirical correlations developed by the Sandia National Lab and implemented through EnergyPlus [34]. Sandia has compiled a database of the empirical correlations required for numerous PV modules, which can then be imported into EnergyPlus. For this simulation a BP Solar BP2140S was chosen. This monocrystalline solar module has similar characteristics to the Solar World 
SW175 modules used to validate the model at Portland State University (see Section 3.4).

The Sandia model accurately predicts daytime PV cell temperatures; however, the model does not allow the PV temperature to fall below the ambient air temperature at night. While nighttime PV temperature is not a consideration for PV power calculations, it is an important element of the rooftop heat island analysis. Our measurements indicate that cooling below ambient air temperatures is expected due to the long wave radiative exchange between the PV panel and the cold night sky. Considering the PV panel energy balance, the panel temperature is expected to fall somewhere between the ambient air temperature and the sky temperature. With this in mind a simple correction to the Sandia model is proposed here for hours between sunset and sunrise:

$$
T_{P V, n i g h t}=0.3 * T_{C}+0.7 * T_{S k y}
$$

The coefficient (blending factor of 0.7 ) in this relationship has been optimized based on data from our validation tests (Section 4).

\subsubsection{EnergyPlus Sky Temperature and View Factor Modification}

In EnergyPlus the sky temperature and roof surface temperature are used to calculate the diurnally-varying long wave radiation balance of the rooftop. The software is incapable, however, of directly computing the change in this longwave exchange caused by the presence of PV panels on the roof. As a workaround to this problem we have introduced a simple scaled sky temperature 
$\left(\mathrm{T}_{\text {sky }}{ }^{*}\right)$ that approximates this effect. Specifically, the new sky temperature used by EnergyPlus in the calculation of the rooftop longwave energy exchange is given by:

$$
T_{s k y}{ }^{*}=0.85^{*} T_{P V}+0.15^{*} T_{s k y} .
$$

Although the scaled sky temperature might be better represented by a $4^{\text {th }}$ power scaling, the linear blending was chosen for computational simplicity and was found to adequately represent the actual nocturnal longwave exchange.

Here, the scaling ratio was determined through analysis of observational data (see Section 3.4). The same scaling argument applies to the short wave energy balance. Thus, in the weather file we reduced solar radiation data by a factor of 0.15 to represent the average reduction of solar radiation incident on the PV-shaded roof.

\subsubsection{EnergyPlus Simulation For Shaded Roof}

With the radiation budget of a PV-shaded roof accounted for, an EnergyPlus simulation was run for each city. EnergyPlus output data were then used to calculate the sensible flux for the shaded roof. In the shaded roof case, sensible heat flux is considered from three roof elements: the shaded roof area, the unshaded roof area, and both sides of the PV panels. The flux from the shaded roof area was calculated using the output of the shaded roof model just introduced. The flux from the unshaded roof area is equivalent to that already calculated using the unmodified EnergyPlus model of the unshaded roof. The flux 
from the PV panel surfaces is calculated using the DOE-2 convection algorithm applied to both sides of the PV panels. For the PV convection, a simplifying assumption that the top of the PV panels is windward, and the bottom is leeward was used.

\subsubsection{Mixing of Shaded, Unshaded and PV Flux}

The final step in the modeling process was to mix the outputs from the shaded, unshaded and PV temperature models. Consideration was given to the changing ratio between shaded and unshaded roof area as the sun moves across the sky. This was done by calculating a shade/sun ratio using the solar angles output from EnergyPlus for each simulation. The solar geometry is shown in Figure 12.
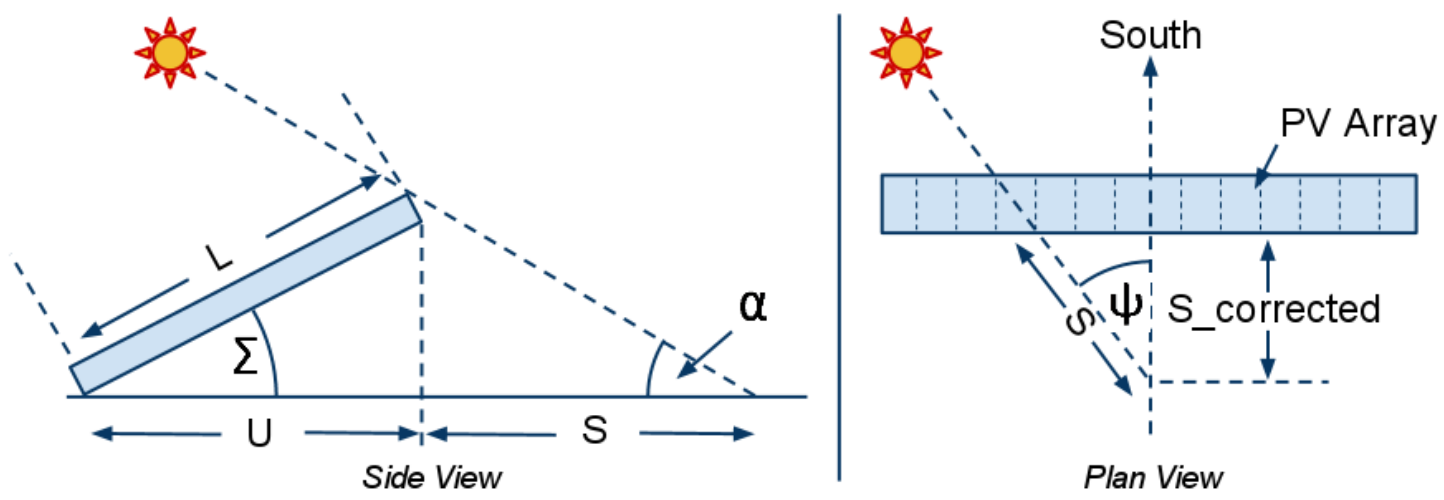

Plan View

Figure 12: Solar geometry used to determine ratio of shaded to unshaded roof area. Side view depicts sun at an azimuth angle of zero degrees.

In this figure, $\Sigma$ is the panel tilt angle, $\alpha$ is the solar altitude, $\Psi$ is the solar azimuth, $L$ is panel length, $U$ is the projected panel length, $S$ is the hypotenuse shadow length, and S_corrected is the North-South shadow length. 
At a given moment, the shaded area $(\mathrm{SA})$ is given by $\left(\mathrm{U}_{+} \mathrm{S}_{-}\right.$corrected $)$ multiplied by a unit depth. The following equations apply:

$$
\begin{aligned}
& S A=U+S, \\
& U=L^{*} \operatorname{Cos}(\Sigma), \\
& S=L^{*} \operatorname{Sin}(\Sigma) / \tan (\alpha), \\
& S \text { corrected }=S^{*} \operatorname{Cos}(\Psi),
\end{aligned}
$$

With the ratio between shaded and unshaded roof area determined, the net flux per $\mathrm{m}^{2}$ of roof area can be calculated as shown in Figure 13. The final mixing equation is given by:

$$
Q_{\text {net }}=Q_{\text {shade }}{ }^{*} S A+Q_{\text {sun }}{ }^{*}(1-S A)+Q_{P V}{ }^{*} A r e a P V,
$$

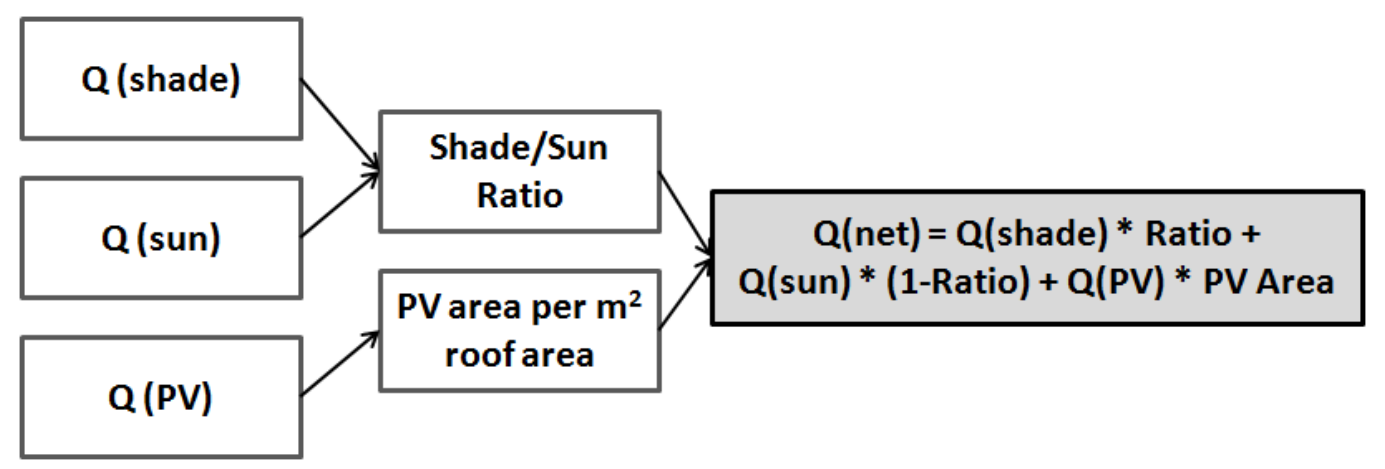

Figure 13: Procedure for calculating the net sensible flux for each roof element.

\section{Model Validation with Measured Data}

\subsection{Surface Temperature Data Collection}

The EnergyPlus model was validated with rooftop temperature data measured on Science Building 2 at Portland State University, Portland, Oregon, 
USA. A portion of the roof with a single array of four 175 watt photovoltaic modules was chosen. Each PV module is $1.6 \mathrm{~m}$ by $0.81 \mathrm{~m}$ in dimension, mounted in a portrait orientation. The panels are spaced $0.30 \mathrm{~m}$ apart installed at an angle of $30^{\circ}$ from the horizontal with the lower edge located $0.15 \mathrm{~m}$ above the roof surface. The existing roof in this area is constructed with a white TPO (ThermoPlastic Polyolefin) membrane. Two sections of black membrane were temporarily installed for this study. Rooftop surface temperatures were measured approximately in the middle of the shaded area directly below each PV panel and also in the unshaded regions in front of the panels (see Figure 14).

Photovoltaic panel temperatures were also measured on a nearby solar array with a total of 8 thermocouples mounted on the underside of the panels.

Radiative properties of the membranes were measured using a reflectometer for long wave emissivity, and a spectrophotometer for albedo [36]. The measured black membrane had an emissivity of 0.91 and an albedo of 0.066. The white membrane had an emissivity of 0.92 and an albedo of 0.58 . 


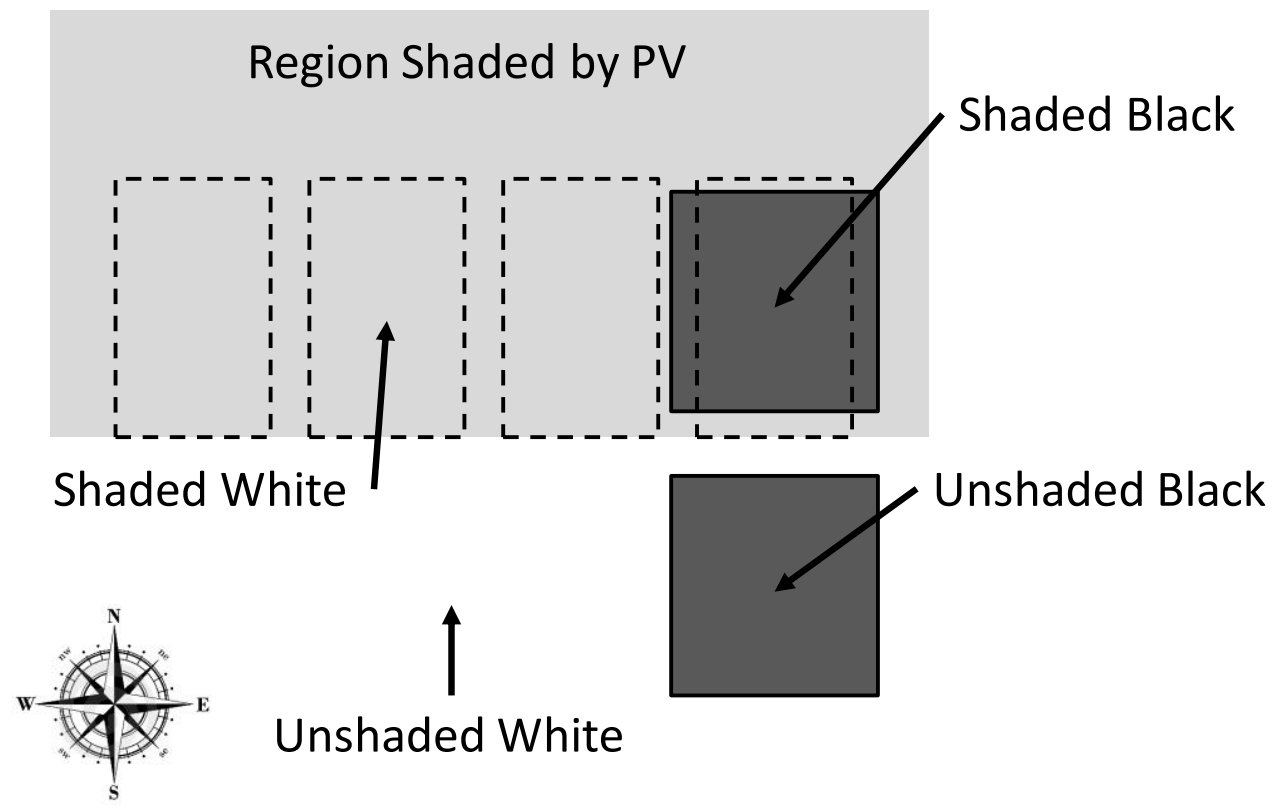

Figure 14: Experiment layout used for model validation.

\subsection{Weather Data}

For model validation, actual weather observed during the validation period was obtained from a site-located weather station. Data from this station was used to modify the following parameters in the EnergyPlus simulation of the experiment: dry bulb temperature, dew point, relative humidity, wind speed, wind direction, global horizontal radiation, direct normal radiation and diffuse horizontal radiation. All remaining weather parameters were left unchanged from the original EnergyPlus weather file used.

Validation was performed using data measured from September 24, 2010 through September 30, 2010. The observed weather during this period is summarized in Table 4 below. 
Table 4: Portland, OR weather observation during validation period in 2010.

\begin{tabular}{lcccc}
\hline Date & $\begin{array}{c}\text { Max } \\
\text { Temp } \\
(\mathrm{C})\end{array}$ & $\begin{array}{c}\text { Min } \\
\text { Temp } \\
(\mathrm{C})\end{array}$ & $\begin{array}{c}\text { Max Total Horizontal } \\
\text { Radiation } \\
\left(\mathrm{W} / \mathrm{m}^{2}\right)\end{array}$ & $\begin{array}{c}\text { Max Wind } \\
\text { Speed }(\mathrm{m} / \mathrm{s})\end{array}$ \\
\hline Sept. 24 & 24.4 & 11.3 & 540 & 3.6 \\
Sept. 25 & 26.6 & 12.5 & 628 & 4.5 \\
Sept. 26 & 20.3 & 16.5 & 234 & 5.8 \\
Sept. 27 & 31.5 & 17.3 & 605 & 3.6 \\
Sept. 28 & 26 & 18.2 & 500 & 6.7 \\
Sept. 29 & 26.3 & 15 & 613 & 7.6 \\
Sept. 30 & 30.7 & 13.7 & 611 & 4
\end{tabular}

\subsection{PV Temperature Model Validation}

To optimize the blending factor used in the nighttime PV model (section 3.3.2), the modeled PV temperature was compared to measured PV temperatures. An iterative approach was used to modify the model mixing ratio between 0.1 and 1.0. The root mean square error (RMSE) was used to measure goodness of fit. It was found that a minimum RMSE of $1.8^{\circ} \mathrm{C}$ occurs with a blending factor of 0.7 . Figure 15 shows the model performance from September 24-30, 2010.

In addition to verifying accurate modeling of surface temperatures, the net flux predictions of the model can be analyzed. Three EnergyPlus simulations were run: first using the Sandia PV model, then using the measured PV temperatures, and finally using the modified Sandia model with a blending ratio of 0.7 . The total flux for each day was calculated and then averaged. The resulting errors were $20.7 \%$ for the Sandia model, and $5.75 \%$ for our modified version of the Sandia model. 


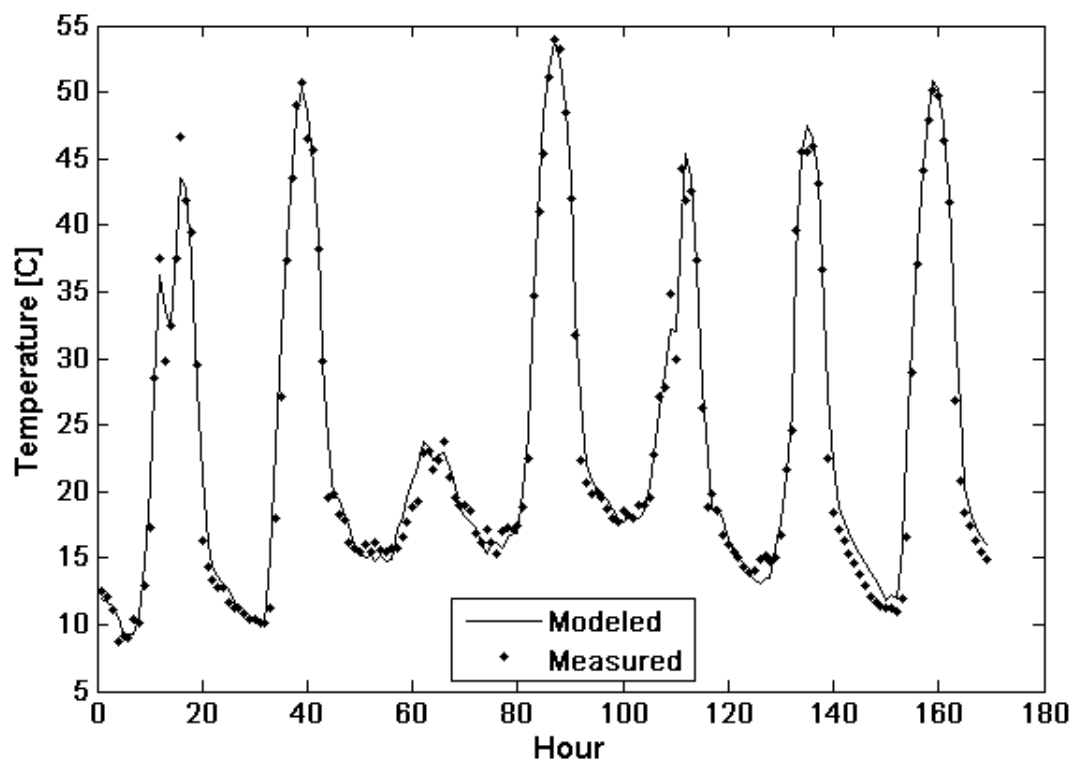

Figure 15: Modeled vs. measured PV surface temperature for the period September 24-30, 2010.

\subsection{Sky View Factor Selection/Validation}

A sensitivity analysis was used to determine an appropriate effective view factor for the shaded area of a PV roof. Simulations were run for PV view factors ranging from $65 \%$ (35\% sky view) to $95 \%$ (5\% sky view). Figure 16 compares the modeled roof temperature to measurements taken at Portland State on a hot, clear day (Sept. 27, 2010). Surface temperature measurements on the shaded roof indicate some anomalous temperature spikes. These spikes are caused by a gap in shading due to the sun shining through the unusually large space between adjacent PV panels at certain sun angles. The observed gap in direct beam shading is not expected on most PV roofs, since panels are typically closely mounted. Temperatures measured on an unshaded roof are also shown in this 
figure to indicate that peak roof temperature occurs between the two spikes seen on the shaded roof. Therefore, the mid-day temperature measured on the shaded roof appears to be representative of the peak temperature expected on a roof with closely spaced panels (which it is our goal to model). With this in mind, it is observed that the peak shaded roof temperature is most closely modeled by using an $85 \% \mathrm{PV}$ view factor.

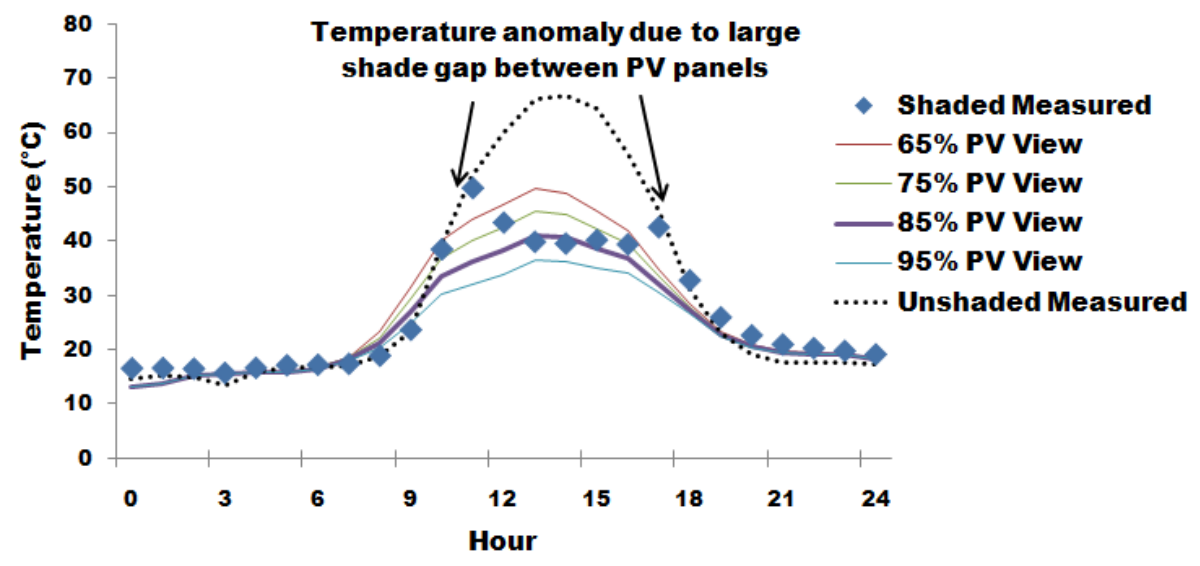

Figure 16: Measured temperature on shaded roof vs. model with varying view factors

\subsection{Unshaded Roof Model Validation}

As shown in Figure 17, EnergyPlus is capable of modeling the white membrane roof surface temperature with a RMSE of $3.1^{\circ} \mathrm{C}$, with similar results obtained for a black membrane. Previous validation has also been conducted for the EnergyPlus green roof module [30]. 


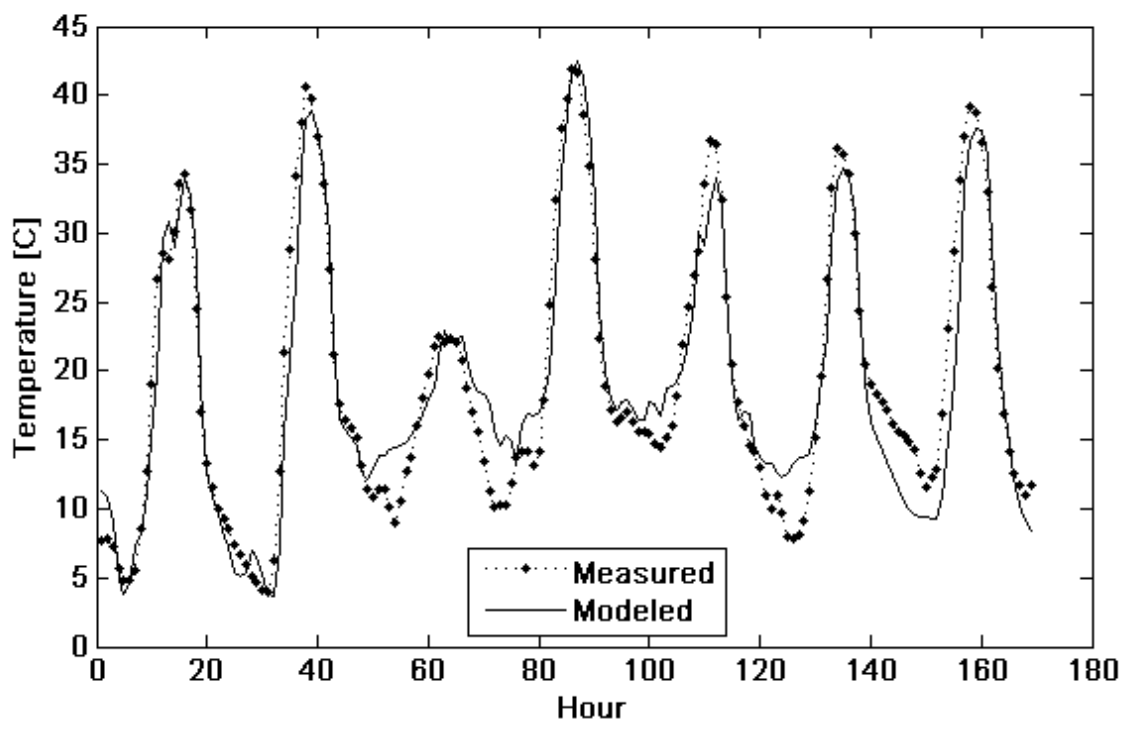

Figure 17: Modeled vs. measured temperature for an unshaded white roof $\left[{ }^{\circ} \mathrm{C}\right]$.

\subsection{Photovoltaic Roof Model Validation}

Validation for the PV-shaded roof model is presented in Figure 18. The measured and modeled temperatures are in close agreement $\left(\mathrm{RMSE}=4.0^{\circ} \mathrm{C}\right)$ for both black and white roof membranes, except for some mid-day temperature spikes seen on the measured data. These short spikes in temperature are caused by the unusually large spacing between PV panels on the Science Building 2 roof. These gaps preclude shading of the roof membrane for a small range of sun angles. As noted above, a more typical PV installation would have minimal gaps between panels, and complete shading can be expected immediately below the panels. Hence, it may be concluded that the PV-shaded roof model is sufficiently capable of modeling the shaded membrane temperature, with an RMSE of less than $4^{\circ} \mathrm{C}$. 


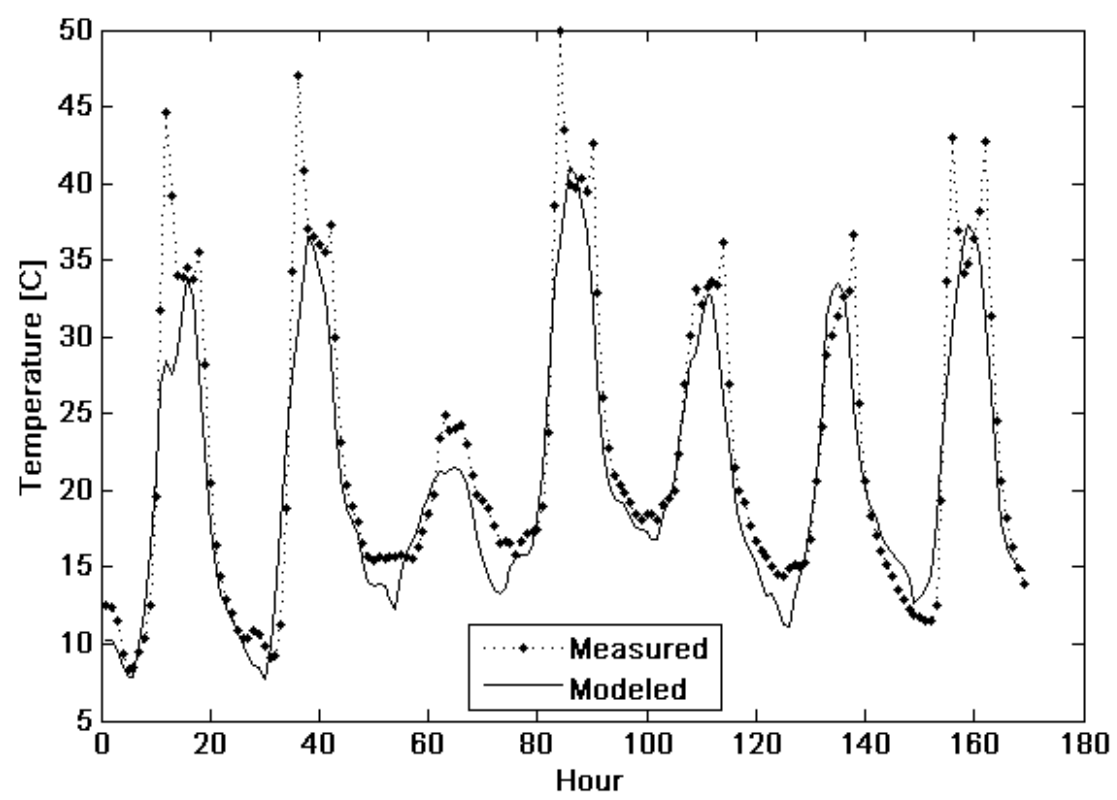

Figure 18: Modeled vs. measured temperature for a shaded black roof $\left[{ }^{\circ} \mathrm{C}\right]$ for September 24-30, 2010.

\section{MM5 Mesoscale Modeling Methods}

For this study, the fifth generation NCAR / Penn State mesoscale model (MM5 Version 3-6-3) was used to model the impact of various roof systems on ambient air temperatures [42]. MM5 is a non-hydrostatic advanced modeling system typically used for weather forecasting and climate studies. The modeling system (Figure 19) is composed of a series of pre-processing programs which are used to develop the inputs required for the final MM5 modeling. Following is a brief description of the pre-processing steps, followed by a description of the MM5 model. Details are available on the MM5 community model website (http://www.mmm.ucar.edu/mm5/documents/). 


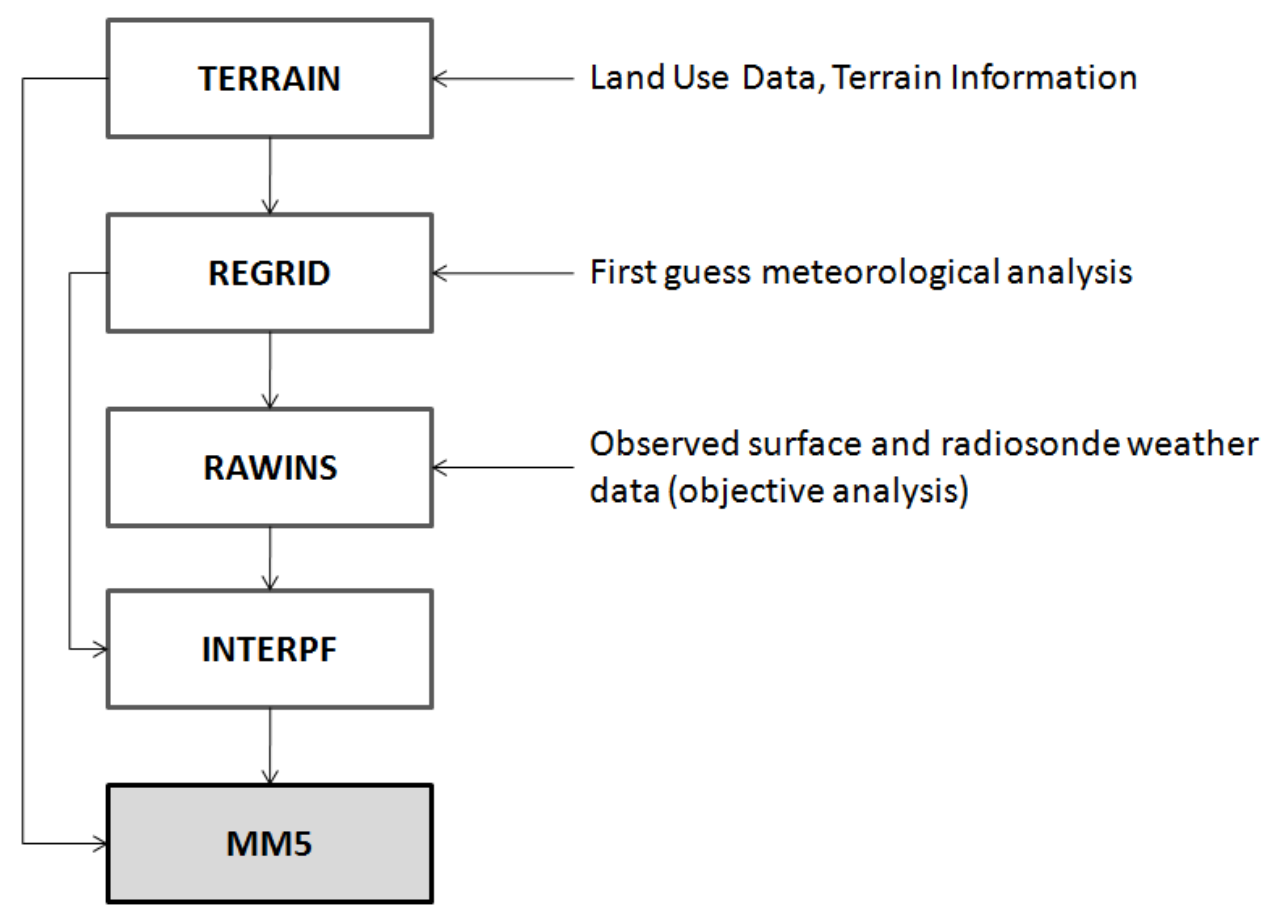

Figure 19: MM5 modeling system.

\subsection{MM5 Pre-Processing Overview}

The first step in creating a MM5 model is to run the TERRAIN program. In this program, information about the local topography and land use is uploaded. This data is then interpolated onto the grid structure of the simulation domain. TERRAIN is also used to establish the domain that will be simulated and specify model nesting parameters.

The next modeling step is REGRID, which is used to establish a first guess for the meteorological elements across the model domain. This is done by reading archived meteorological analyses and forecasts, which are then interpolated to the chosen model domain. Input data typically includes temperature, wind, humidity, pressure, sea temperature and snow cover data. 
Following the first guess supplied by the REGRID program, RAWINS is used to refine the meteorological fields through a process known as objective analysis. Objective analysis takes information gathered from meteorological observations and uses it to develop a more accurate initial model condition. Both surface and radiosonde measurements of temperature, humidity and wind data are used as inputs in the RAWINS program.

Output from RAWINS and REGRID is then processed by INTERPF. The primary goal of INTERPF is to transform the data into the proper form required for the MM5 model. The output of the INTERPF program provides the initial and boundary conditions for the MM5 simulation.

Data sources used for this study are: $2 m$ digital elevation data, USGS 24 category land use with 30 second resolution and NCEP data for REGRID.

\subsection{MM5 Model Description}

Some of the key model parameters and physics options used for this study are described below.

- Forecast Period - A forecast period of 2.5 days (3600 minutes) is used for all simulations. This includes a 12 hour spin-up period, followed by a 48 hour period which is used for subsequent analysis. The simulation period begins on 8/22/2000 at 12:00 AM GMT.

- Nesting - A nested model with 5 domains centered on Portland, OR was used. All five domains are simulated for the full simulation period of 3600 
minutes. A moving nest is not employed, since the primary area of interest is the urban core of Portland. Figure 20 shows the five-domain nesting geometry. Figure 21 and Figure 22 show the innermost domain (domain 5) terrain height and land use classification respectively.

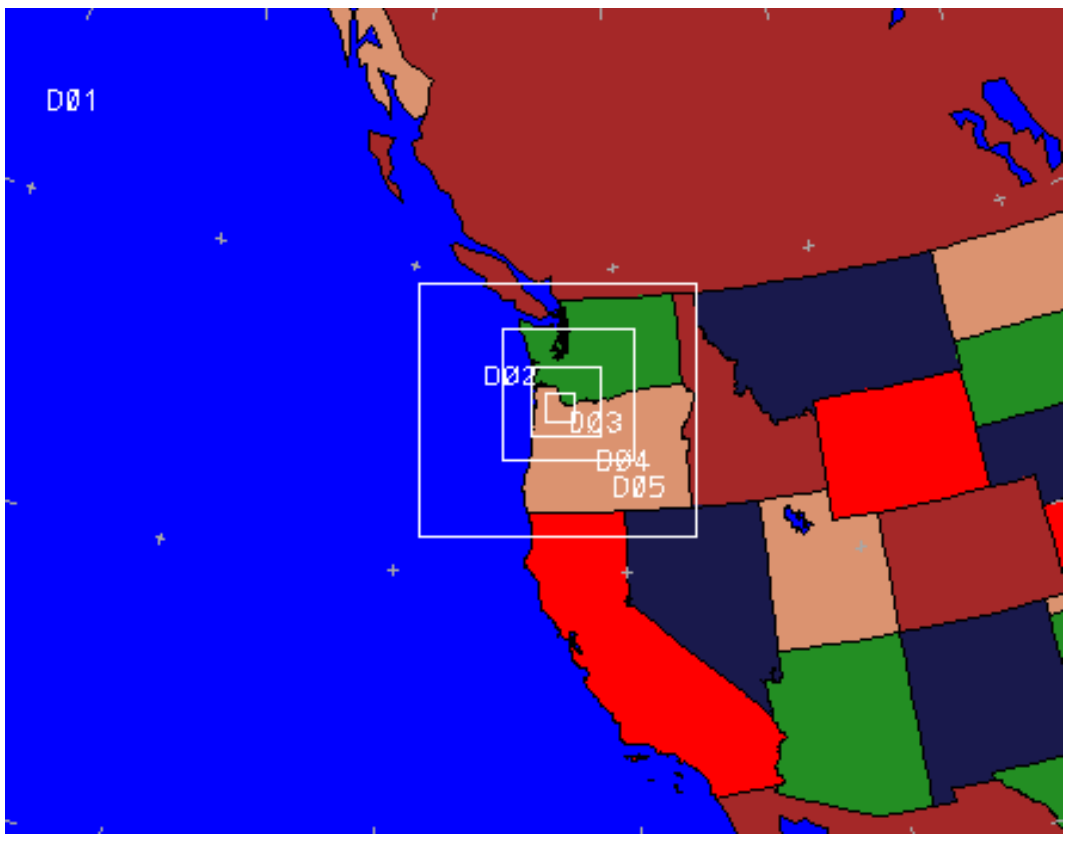

Figure 20: Five-domain nesting used for MM5 simulations. 


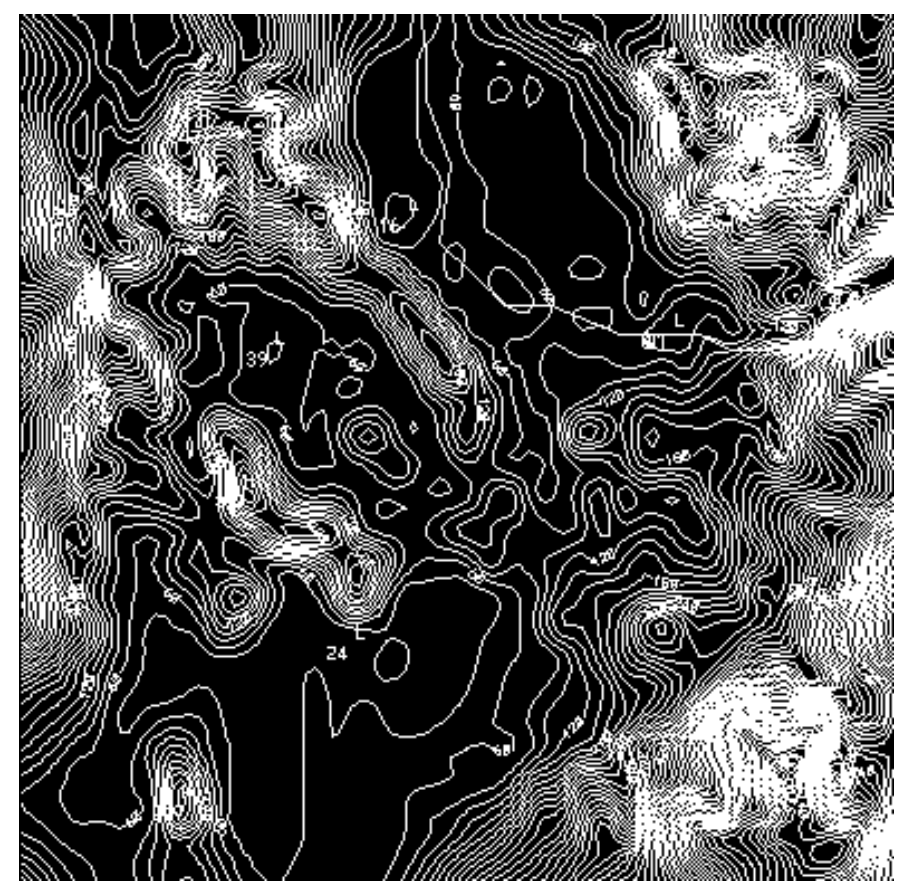

Figure 21: Domain 5 terrain height topographic map centered on Portland.

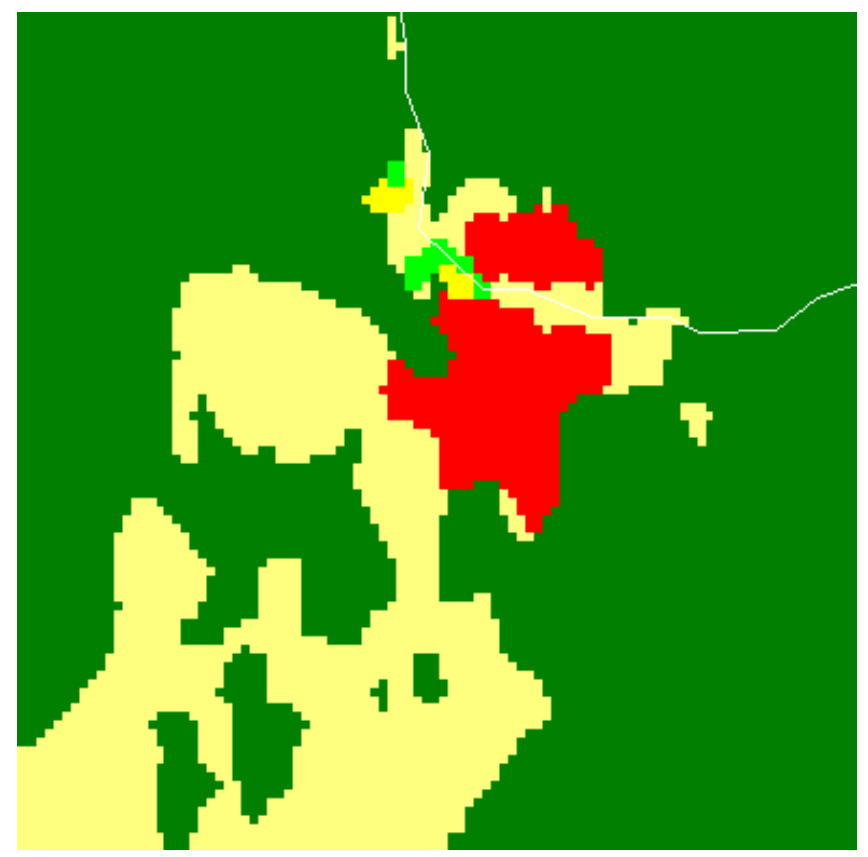

Figure 22: Domain 5 USGS 24 category land use. Prominent categories are: Red - Urban, Tan - Dryland Crop \& Pasture, Green - Needle Leaf Evergreen 
- Grid Size \& Timesteps - The grid size and time step used for each domain is shown in Table 5. A square grid $(\Delta \mathrm{X}=\Delta \mathrm{Y})$ is used, with 35 terrainfollowing vertical $(\sigma)$ layers.

Table 5: Grid size and timesteps used for all simulations.

\begin{tabular}{cccc}
\hline Domain \# & Grid Size $(\mathrm{km})$ & $\sigma$-Layers & Timestep $(\mathrm{sec})$ \\
\hline 1 & 81 & 35 & 240 \\
2 & 27 & 35 & 80 \\
3 & 9 & 35 & 26.67 \\
4 & 3 & 35 & 8.89 \\
5 & 1 & 35 & 2.96
\end{tabular}

- Cumulus Parameterization - Cumulus effects with length scales smaller than the model grid are accounted for using the Grell parameterization. This scheme is based on the rate of destabilization. It is a single-cloud scheme that considers updraft and downdraft fluxes, using their predicted behavior to provide feedback to the resolved grid of meteorological fields. [37].

- Planetary Boundary Layer (PBL) Scheme - The high resolution Blackadar PBL scheme is used for this model. This scheme is used to parameterize the distribution of heat, moisture and momentum in the PBL. The Blackadar scheme distinguishes between unstable and neutral/stable PBL's. Neutral and stable PBL's are handled with a local, first-order closure, K-theory parameterization. Unstable boundary layers are parameterized using a non-local, first-order closure scheme [37]. 
For the current analysis, the Blackadar PBL parameterization has been further modified to accept the additional input of a surface air heat flux profile [38]. This modification was originally developed to study the influence of anthropogenic heating; in this study, it is used to consider the impact of various sensible flux profiles arising from building roof selection. Heat flux is included as an evenly distributed source in the near-surface air. This leads to inclusion of an additional temperature perturbation term in the surface layer potential temperature calculations.

- Explicit Moisture Scheme - The Simple Ice scheme is used to predict precipitation and cloud water content. For reference, there was no rainfall recorded during the simulation and cloud cover was minimal (per NCDC Climate Data).

- Radiation Scheme - The Cloud-Radiation scheme was chosen for this model. This scheme accounts for long and short wave interactions with clouds and clear air to determine surface radiation fluxes.

\subsection{Baseline MM5 Model}

Before simulating the impact of PV panels and various roof combinations, a baseline condition was modeled. The default urban land use parameters, Table 6 , were used as a baseline model. 
Table 6: Default parameters assigned to urban land use category in MM5 model

\begin{tabular}{cccccccccr}
\hline Albedo & $\begin{array}{c}\text { Moisture } \\
\text { Avail. }(\%)\end{array}$ & Emissivity & $\begin{array}{c}\text { Roughness } \\
\text { Length }(\mathrm{cm})\end{array}$ & $\begin{array}{l}\text { Thermal Inertia } \\
\left(\mathrm{cal} / \mathrm{cm}^{2} \mathrm{k} \mathrm{s}^{1 / 2}\right)\end{array}$ \\
\hline Sum & Win & Sum & Win & Sum & Win & Sum & Win & Sum & Win \\
\hline 18 & 18 & 5 & 10 & 0.88 & 0.88 & 50 & 50 & 0.03 & 0.03
\end{tabular}

\subsubsection{Baseline Rooftop Sensible Flux Calculations}

An additional iteration of the EnergyPlus model discussed in section 3 was used to calculate the sensible flux levels for the case of a baseline roof. Since the average of all roof materials in the city is neither black, white or green an additional data set was needed for an "average" roof. To estimate the albedo of this roof, data published in Akbari 1999 [10] was used. Average roof albedo from three cities provides an estimate of the baseline roof albedo for Portland. These measurements are shown in Table 7. Based on these values an estimated baseline roof albedo of 0.25 was chosen for Portland. The "average" roof was then modeled in EnergyPlus to calculate an hourly sensible flux profile.

Table 7: Average roof albedo for three cities. (adapted from Akbari 1999)

\begin{tabular}{cccc}
\hline & Residential & Commercial & Total \\
\hline Atlanta & 0.30 & 0.32 & 0.31 \\
Washington DC & 0.25 & 0.25 & 0.25 \\
Philadelphia & 0.20 & 0.18 & 0.19 \\
Average & 0.25 & 0.25 & 0.25
\end{tabular}




\subsection{MM5 Model Iterations}

Changes to the urban energy balance caused by different roof types were modeled using the modified version of MM5 described in section 5 .

The difference between the flux profile of the "average" roof and each modified roof scenario was used as a flux source/sink in the MM5 model. The model adds a specified amount of heat uniformly to all cells defined by the terrain data as "urban". However, in each urban grid cell, rooftops account for only a portion of the land use.

A coarse estimate of the proportion of urban land area with roof cover was extracted from Google satellite imagery of downtown Portland, as shown in Figure 23. Image processing was used to create a high contrast black and white image. In this image the rooftops appear as white pixels, while the roads and parks appear as black pixels. Although this is not a perfect mapping of land cover, it provides a reasonable approximation for the purposes of this study. A pixel count was used to calculate the roof proportion of a $1-\mathrm{km}^{2}$ region. In this region roofs account for $41 \%$ of the area, with the remaining $59 \%$ divided between streets and parks. For comparison, a previous analysis of orthophotos calculated a roof area of $23 \%$ for downtown Sacramento, CA. [39]. 

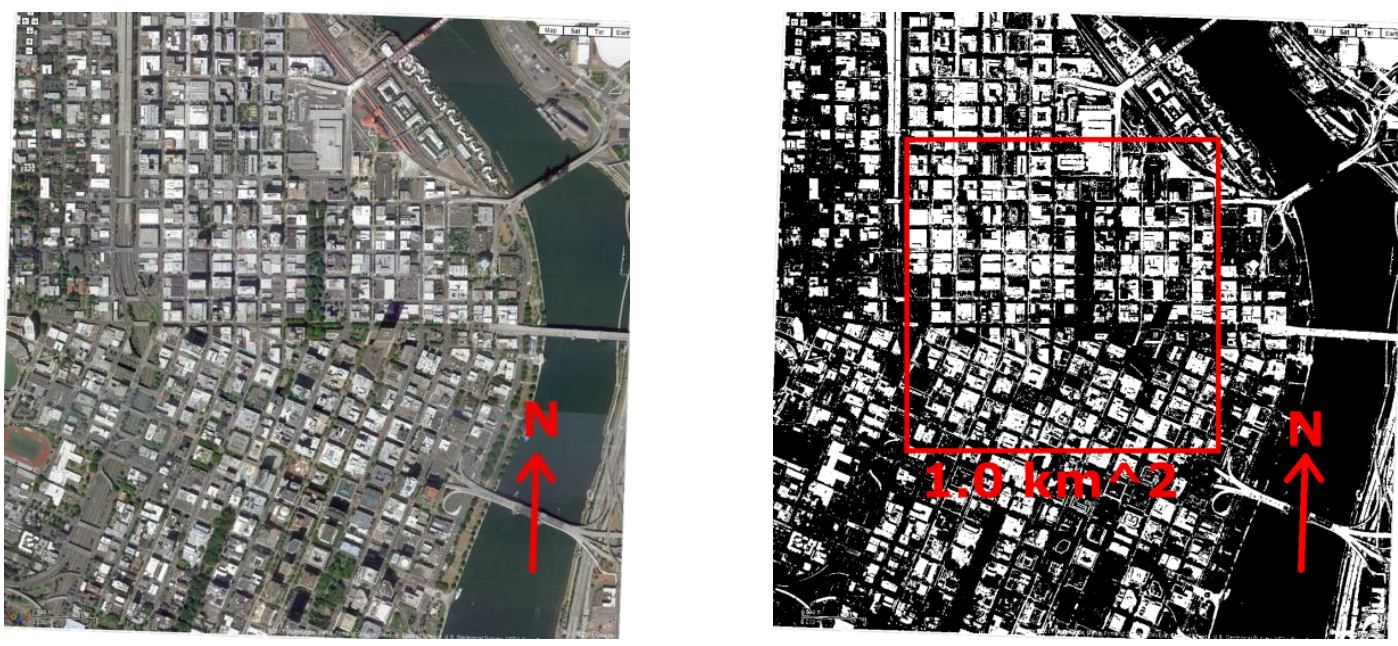

Figure 23: Satellite imagery used to estimate proportion of urban land with roof cover.

The following formula was used to calculate the rooftop hourly flux profile per square meter of urban land cover. An example of the resulting flux profile is given in Figure 24.

$Q_{\text {urban }}=\left(Q_{\text {roof }}-Q_{\text {base }}\right) * 0.41$,

Where:

$Q_{u r b a n}=$ Flux per $^{2}$ of urban area

$Q_{\text {roof }}=$ Flux per m² of modified roof (eg black, white, green, etc)

$Q_{\text {base }}=$ Flux per $m^{2}$ of baseline roof (albedo $=0.25$ )

$0.41=$ Roof area per $m^{2}$ 


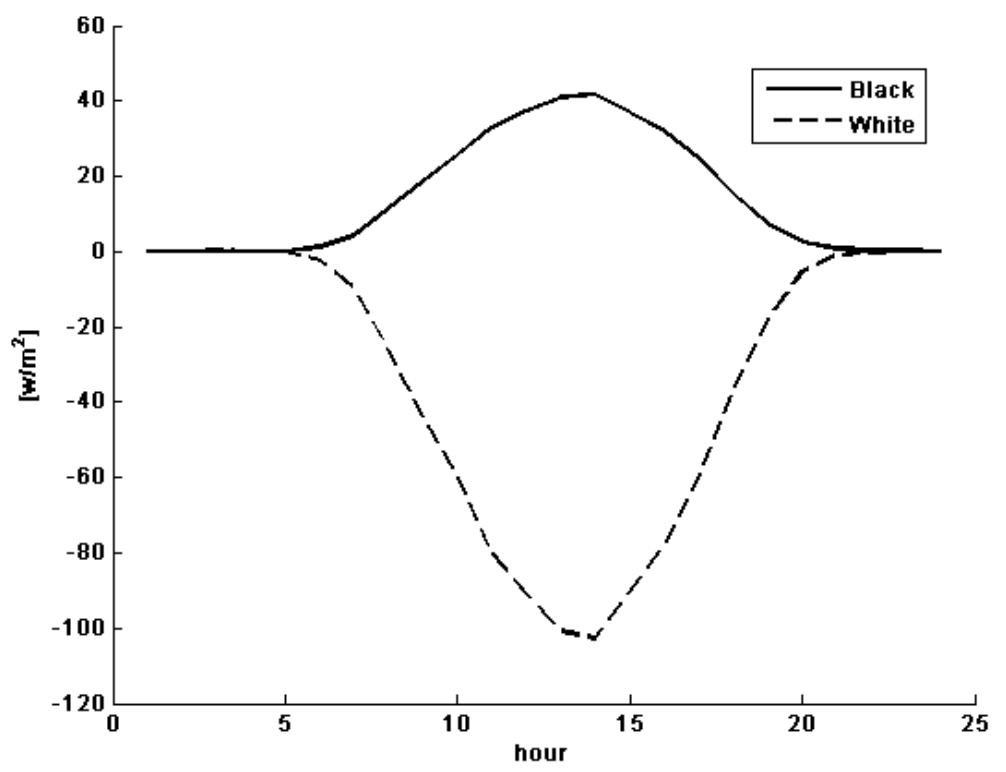

Figure 24: Representative flux perturbation profile used for MM5 model input $\left[\mathrm{W} / \mathrm{m}^{2}\right]$. Derived from EnergyPlus simulations using Portland, OR TMY weather for July 28 with a daytime high temperature of $88.5^{\circ} \mathrm{F}$.

\section{MM5 Model Validation}

To ensure reasonably accurate model performance, a simple validation was performed. Airport weather data from the station at Portland International Airport is compared with the MM5 model output for August 22-23, 2000 [40].

Figure 25 shows close agreement between the modeled and measured data, with anomalies in maximum and minimum temperatures (modeled T - Measured $\mathrm{T})$ of $1.2,-1.5,1.3$ and $-1.8^{\circ} \mathrm{C}$ from left to right on figure. 


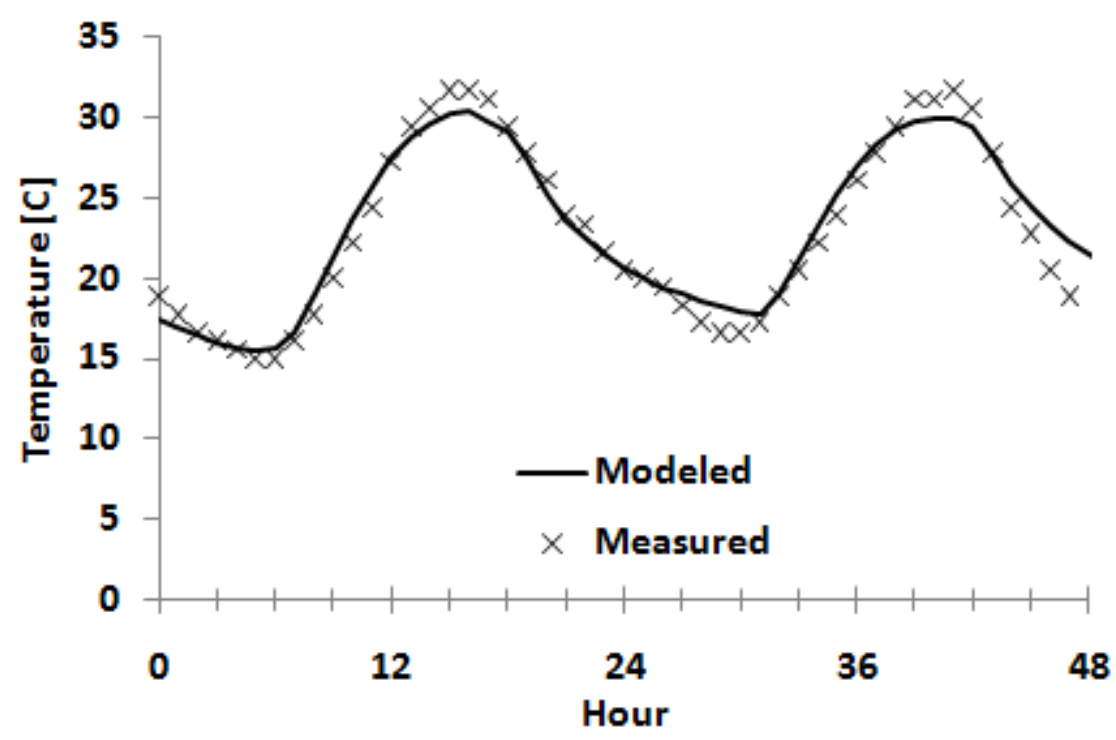

Figure 25: Validation of MM5 model with historic meteorological observations from PDX Airport. August 22-23, 2000.

\section{Results \& Discussion}

\subsection{Sensible Flux Modeling Results \& Discussion}

The typical 24 hour summer temperature profile of an unshaded roof is shown in Figure 26. This plot shows the profile for a hot day in Chicago, but similar trends are seen for all modeled cities. The black and white roof both start at the same overnight temperature (10pm through $5 \mathrm{am})$, but begin to warm at different rates during the day. In contrast, the green roof (soil surface temperature) starts at a higher night temperature due to heat retained by its thermal mass. By mid-day the black roof is approximately $71^{\circ} \mathrm{C}$, while the white and green roofs reach peak temperatures of $47-49^{\circ} \mathrm{C}$.

Figure 27 shows the flux profile for the same day in Chicago. An important observation is that the black and white roofs both have negative flux at night, 
while the green roof does not. This is a result of the black and white roof reaching temperatures below the ambient air temperature due to radiative cooling. The green roof maintains a higher temperature due to thermal mass and a reduced view of the sky due to vegetation. This is consistent with measurements from prior studies such as [9], which found that nighttime green roof temperatures were $7^{\circ} \mathrm{C}$ warmer than a light membrane.

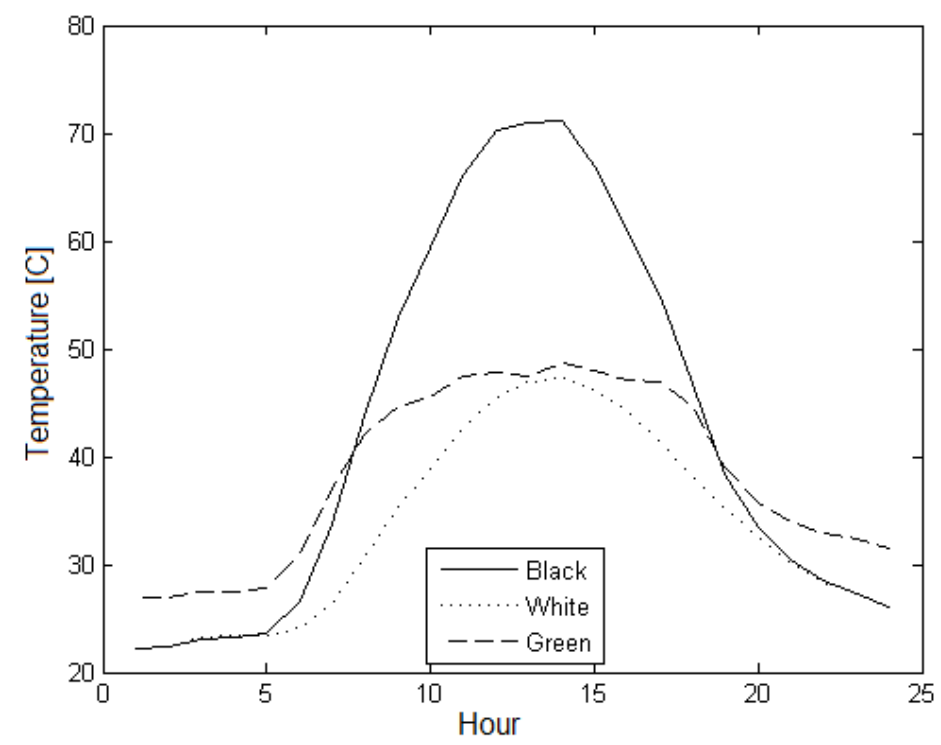

Figure 26: Temperature Profile for Chicago, July $24\left[{ }^{\circ} \mathrm{C}\right]$. 


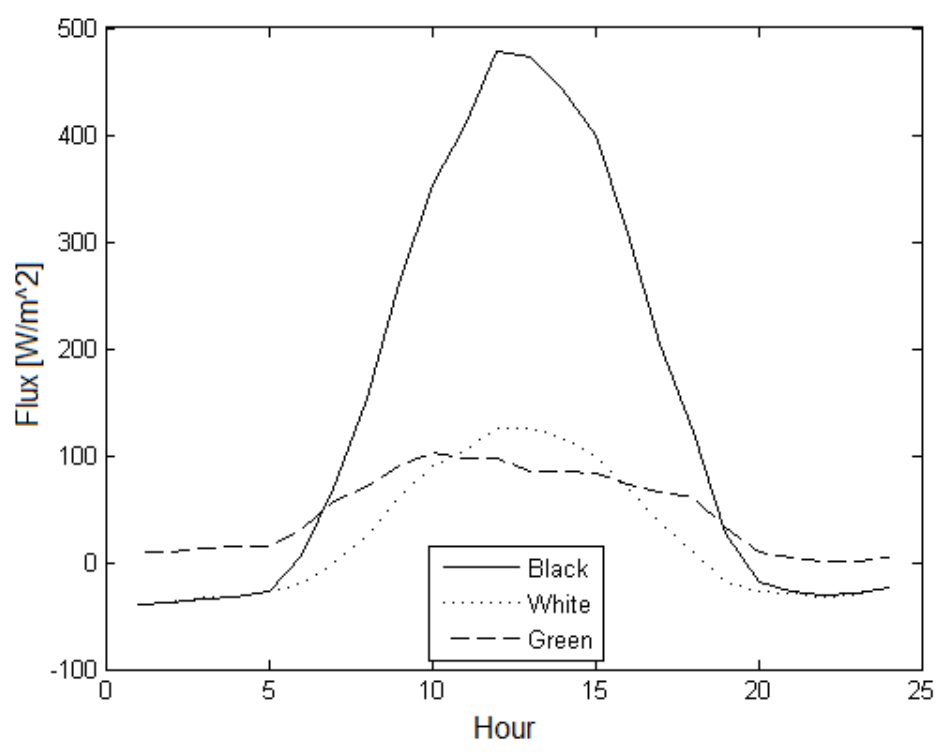

Figure 27: Flux Profile for Chicago, July $24\left[\mathrm{~W} / \mathrm{m}^{2}\right]$.

In the analysis that follows, instead of considering a diurnal flux profile, the data are presented in terms of either peak daily flux or total flux. Total flux is the net flux integrated over a 24 hour period.

In Figure 28a, the maximum flux for each day is computed, and then averaged for the summer period - from June 1 through August 31. This gives a summertime value for the mean peak daily flux per unit roof area. In all cities the black roof and black-PV roof have the highest peak flux magnitudes. For these roofs, the average peak flux ranges from 331 to $405 \mathrm{~W} / \mathrm{m}^{2}$. Similarity between the black and black-PV roofs implies that any reduction in roof membrane flux as a result of PV shading is balanced by the addition of flux from the top and bottom surface of the PV panel. 

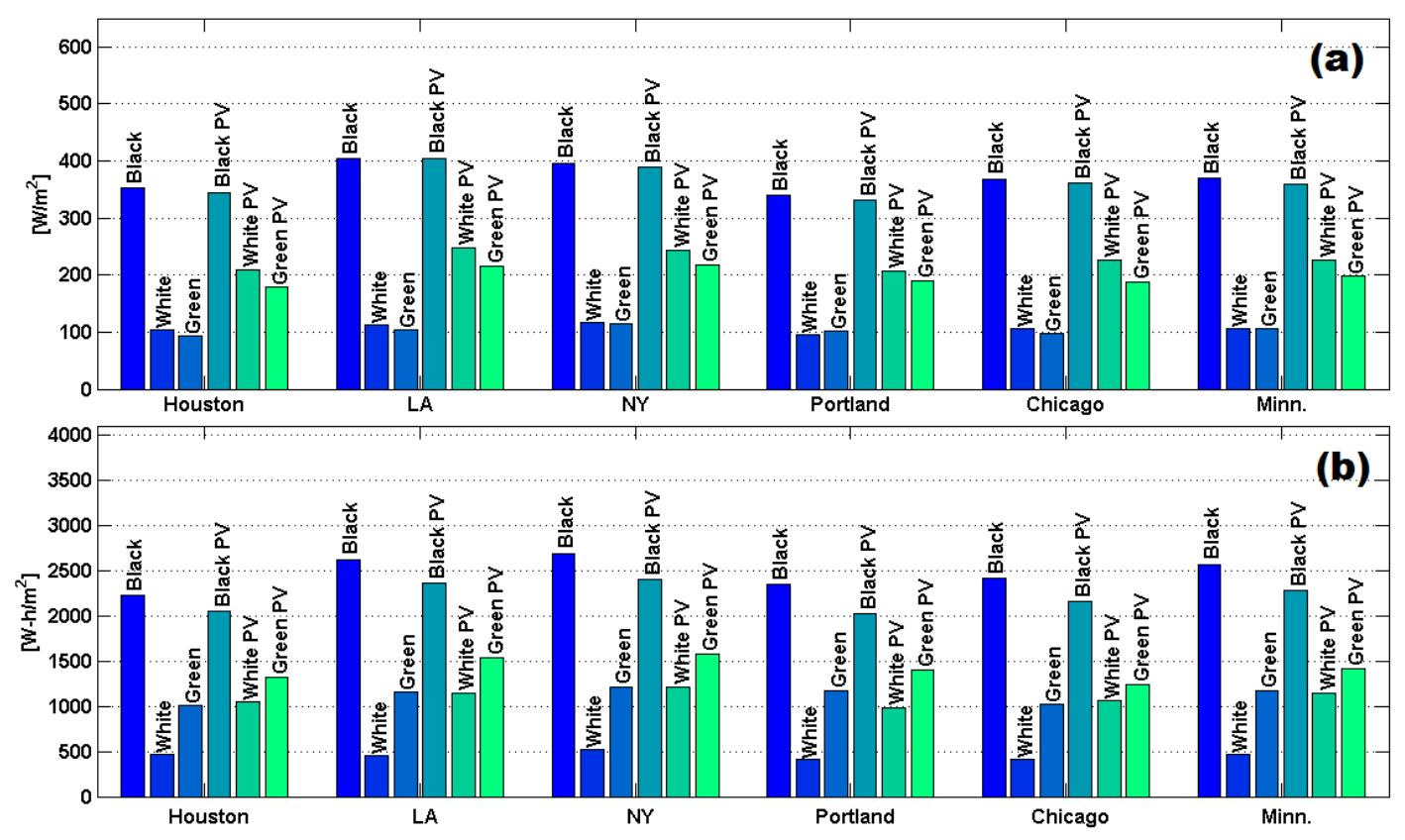

Figure 28: (a) Summer mean peak daily flux $\left[\mathrm{w} / \mathrm{m}^{2}\right]$ (b) Summer mean total daily flux $\left[\mathrm{W}-\mathrm{h} / \mathrm{m}^{\wedge} 2\right]$

In addition to analyzing peak fluxes, the total daily flux was also calculated. The total flux for each day is then averaged for the summer months from June 1 through August 31. The resulting mean total daily flux per unit area of roof is presented in Figure 28b.

The total flux generally follows the same trend seen in the peak flux, with one significant exception. In both the unshaded and PV-shaded cases, the green roof has higher flux magnitudes than a white roof due to its thermal mass. While the white roof is able to quickly cool to ambient (or often lower) temperatures at night, the residual heat built up in a green roof is slowly released during the night. In order to more clearly demonstrate differences among roofs, the mean peak daily flux and mean total daily flux data are presented again in Figure 29 as 
percent reductions relative to a black roof. Across all cities, the unshaded white roof and unshaded green roof yield the highest reduction in peak fluxes at $71 \%$ and $72 \%$ respectively. With respect to total daily flux, consistent results are seen across all cities, with white roofs yielding the highest reduction (82\% on average). Also noteworthy is that the addition of PV panels to a black roof reduces the total flux, on average across all cities, by $11 \%$.
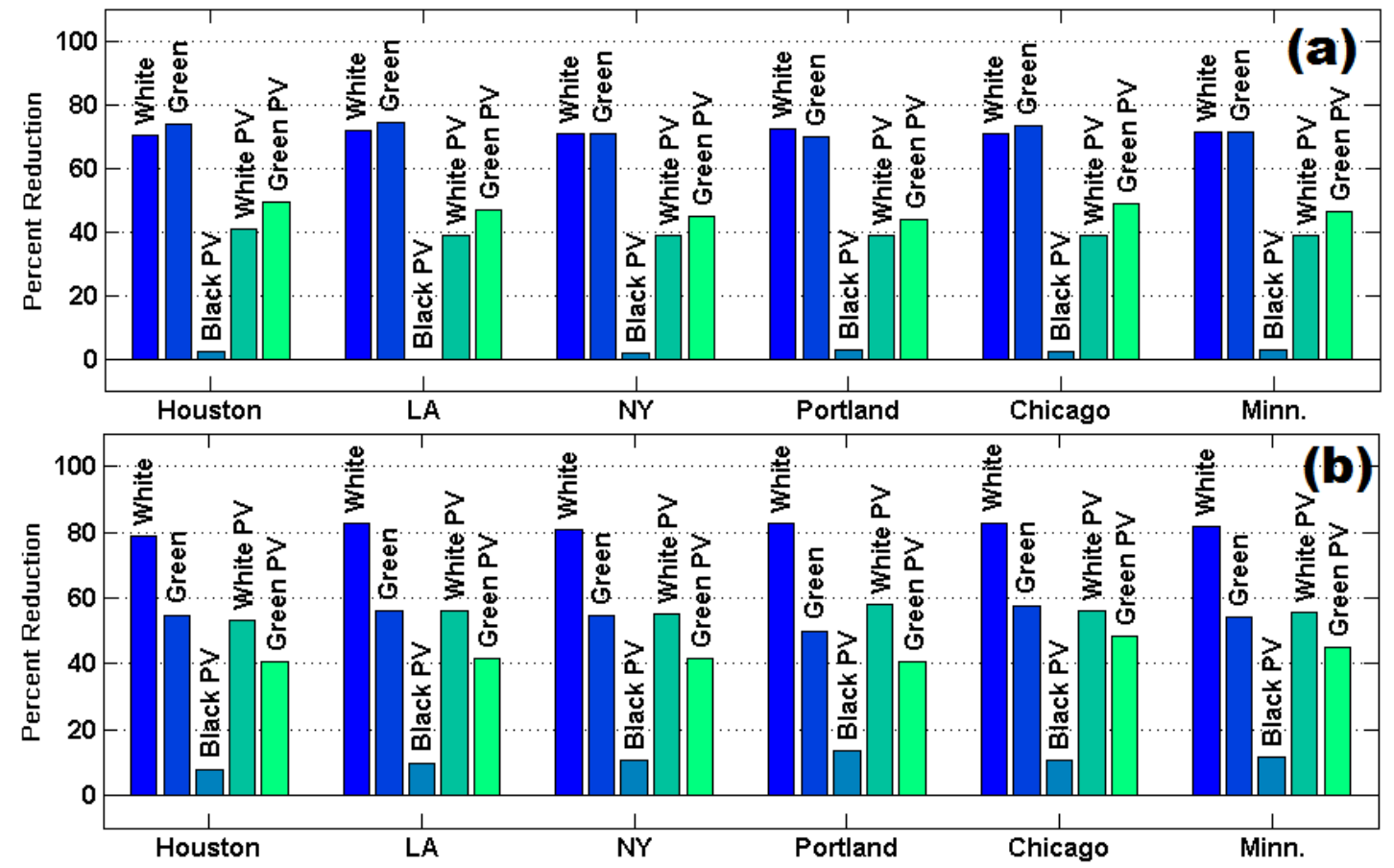

Figure 29: Summer mean percent reduction in: (a) peak, (b) total, daily flux from black roof levels.

To highlight the result of adding PV to a roof, Figure 30 shows the "PV UHI Penalty" for each roof type. The PV UHI penalty is simply the difference in flux between an unshaded roof, and a PV-shaded roof. The addition of PV to a white or green roof, on average across all cities, increases the peak flux by 120 $\mathrm{W} / \mathrm{m}^{2}$ and $95 \mathrm{~W} / \mathrm{m}^{2}$, respectively. The corresponding total fluxes increase by 641 
$\mathrm{W}-\mathrm{h} / \mathrm{m}^{2}$ (white) and $291 \mathrm{~W}-\mathrm{h} / \mathrm{m}^{2}$ (green). It should be noted that a black roof has a negative PV UHI penalty for all cities (except for the case of peak flux for LA, where it is almost neutral). This implies that adding PV to a black roof actually improves the roof's overall summertime heat island impact. On average, the total flux for a black roof is reduced by $264 \mathrm{~W}-\mathrm{h} / \mathrm{m}^{2}$.
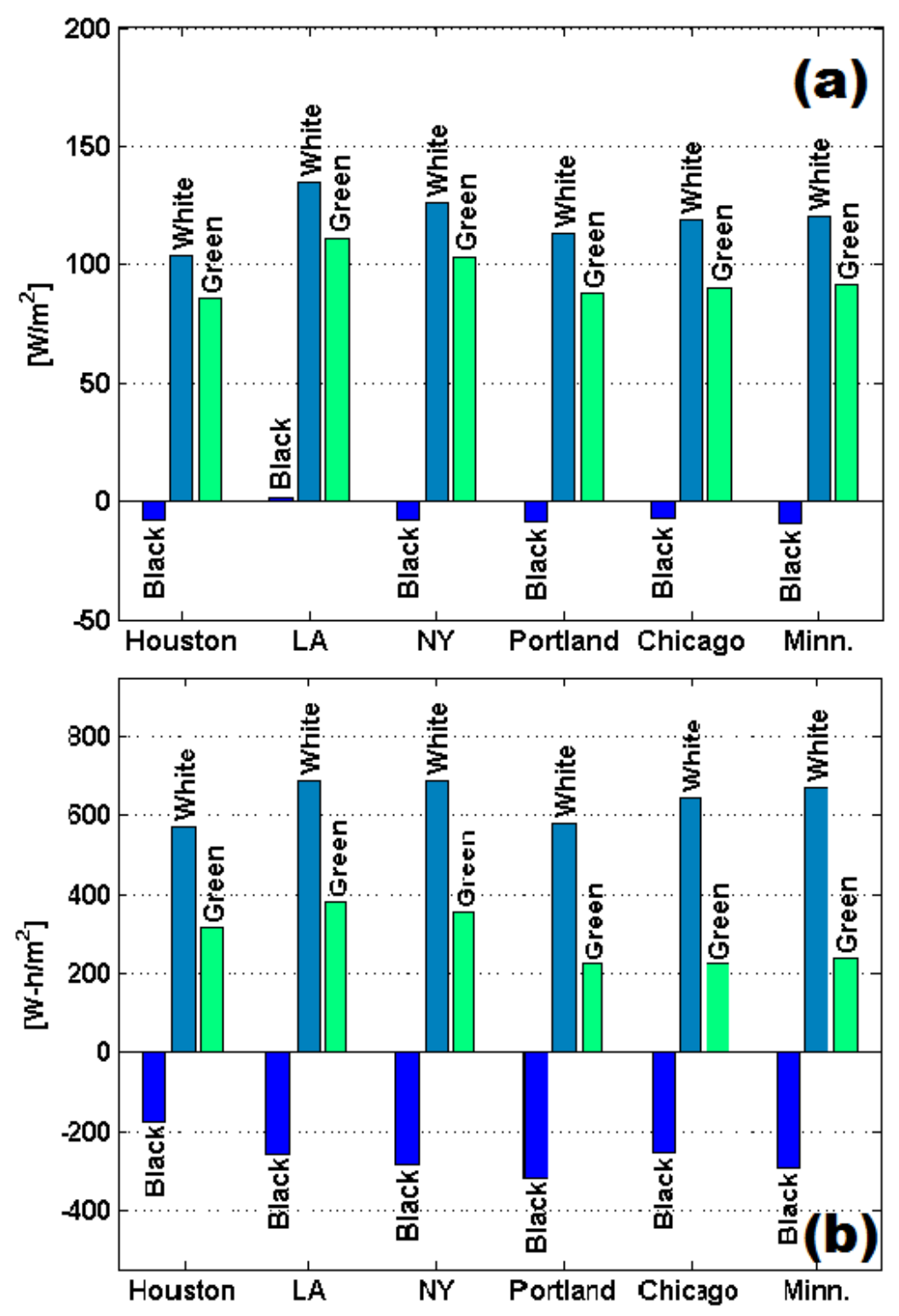

Figure 30: PV UHI Penalty - (a) peak flux, (b) total flux 
Another important consideration when adding PV to a roof is how it might affect the rooftop surface temperature and hence the magnitude of heat flux into the building. Figures 31 through 33 compare the 24 hour profile of roof membrane surface temperatures for various roof types in Chicago on a hot day (July 24 using TMY weather data). For each roof type (black, white, green) the addition of PV panels reduces the roof membrane surface temperature. For comparison, the temperature difference between a base roof and the same roof with PV panels is calculated and displayed in Table 8. Reductions in peak daily temperature of $16.2,4.8$ and $8.5^{\circ} \mathrm{C}$ are seen for the cases of black, white and green roofs respectively.

Table 8: Reduction in roof temperature due to addition of PV panels $\left[{ }^{\circ} \mathrm{C}\right]$. Data shown for Chicago on July 24 using TMY weather. Black and white roof indicate membrane temperature, green roof indicates soil surface temperature.

\begin{tabular}{ccccc}
\hline \multirow{2}{*}{ Base Roof Type } & \multirow{2}{*}{ Local Time } & \multicolumn{3}{c}{ Roof Membrane $\Delta \mathrm{T}$ : Base $-\mathrm{PV}\left[{ }^{\circ} \mathrm{C}\right]$} \\
\cline { 3 - 5 } & $2 \mathrm{pm}$ & Base & $\mathrm{PV}$ & $\Delta \mathrm{T}$ \\
\hline Black & $2 \mathrm{pm}$ & 47.1 & 54.9 & 16.2 \\
White & $2 \mathrm{pm}$ & 48.8 & 42.5 & 4.8 \\
Green & & & & \\
\hline
\end{tabular}

It appears the PV panels are an effective method of shading the roof membrane from intense mid-day solar radiation. Even a highly reflective white roof benefits from this additional shading, despite the increase in long wave radiation transmitted from the hot PV panels to the cooler white membrane beneath them. This finding suggests that any increase in building energy use 
caused by additional urban atmospheric warming will be at least partially offset by an energy savings resulting from lower rooftop membrane temperatures.

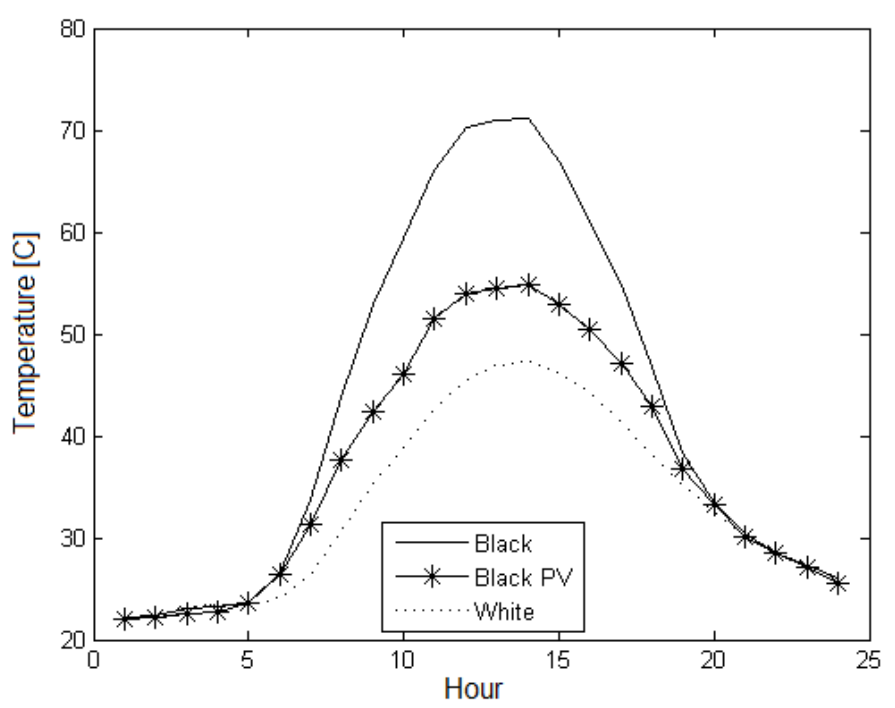

Figure 31: Impact of PV panels or black roof membrane temperature $\left[{ }^{\circ} \mathrm{C}\right]$. Chicago, July 24 . White membrane temperature shown for comparison.

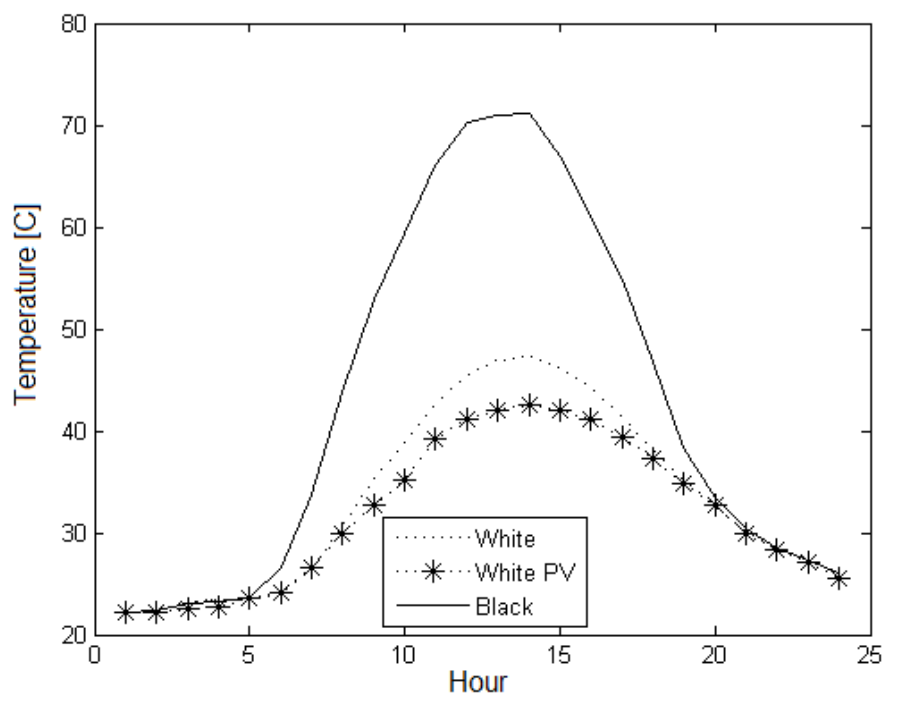

Figure 32: Impact of PV panels or white roof membrane temperature $\left[{ }^{\circ} \mathrm{C}\right]$. Chicago, July 24. Black membrane temperature shown for comparison. 


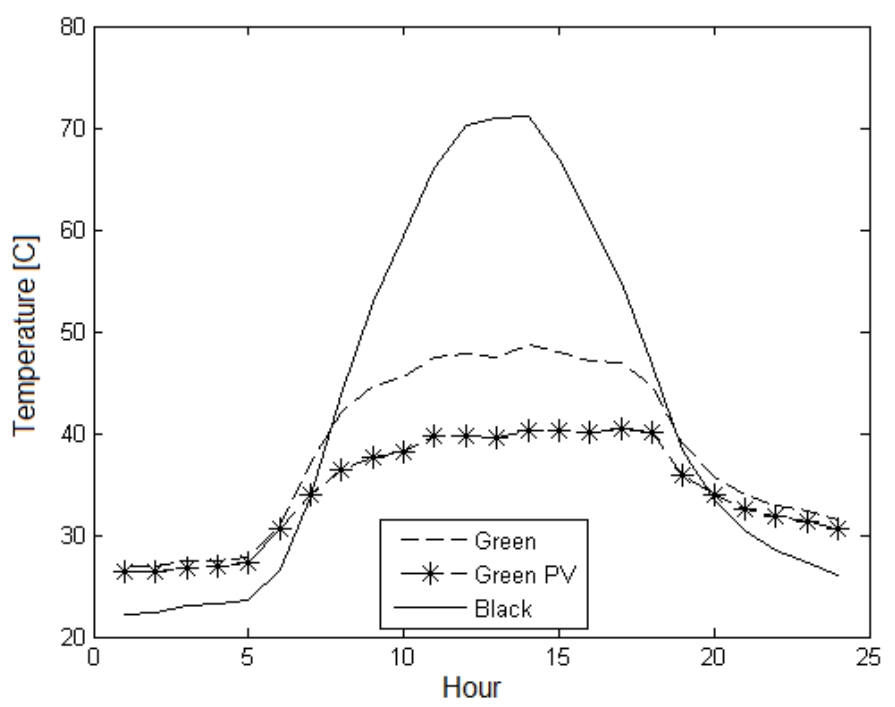

Figure 33: Impact of PV panels or green roof membrane temperature $\left[{ }^{\circ} \mathrm{C}\right]$. Chicago, July 24 . Black membrane temperature shown for comparison.

\subsection{Mesoscale Climate Modeling Results \& Discussion}

Using the methods described in section 5, the MM5 mesoscale meteorological model was used to predict urban air temperatures resulting from various roofing choices. Modeling was performed for August 22-23, 2000. Figure 34 shows the modeled results for ambient near-surface air temperature during this period with a baseline roof albedo of 0.25 . The period chosen for testing represents a hot, but not extreme, summer day in Portland, OR. 


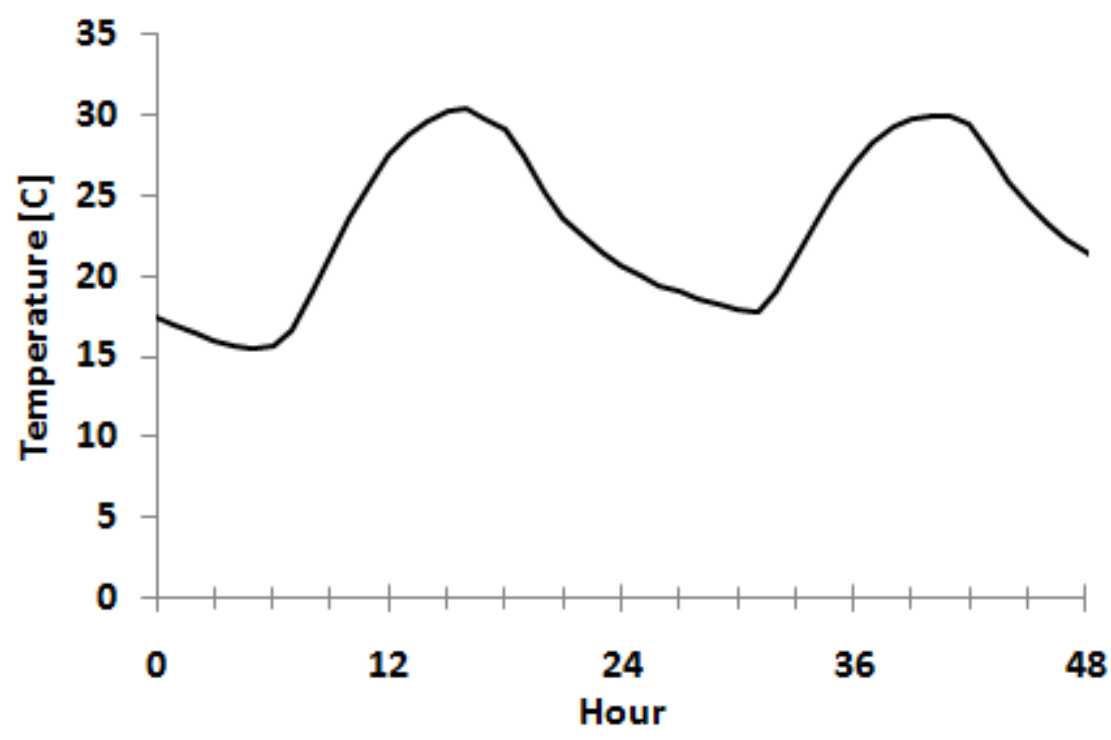

Figure 34: Modeled near-surface air temperature [C] for 8/22-8/23/2000 with baseline roof albedo of 0.25 .

Setting the existing roof composition as a baseline, various alternatives were then modeled to evaluate the sensitivity of urban air temperature to different roofing systems. Since a switch to darker roofing is not expected, only the cases of white roof, white-PV roof, green roof and green-PV roof are evaluated. Figure 35 shows the change in near-surface air temperature when the cases of white and white PV roofs are modeled. In the white roof case, peak reductions on the order of $1^{\circ} \mathrm{C}$ are seen on both days at approximately $12 \mathrm{pm}$.

Interestingly, the white PV roof shows only small reductions of less than $0.5^{\circ} \mathrm{C}$ at mid-day. However, greater reductions of approximately $1^{\circ} \mathrm{C}$ are seen overnight. In comparison with the unshaded white roof, the white PV roof has high daytime flux due to the hot PV surface. At night, both the PV surface and roof surface cool below the ambient air temperature through long wave radiative 
exchange with the sky. This flux profile is shown in Figure 36. The chilled PV and roof surfaces act to cool the ambient air. This indicates that the addition of PV panels to the urban environment adds cool surface area and increases the nighttime cooling potential of a roof, but does create a daytime penalty as expected.

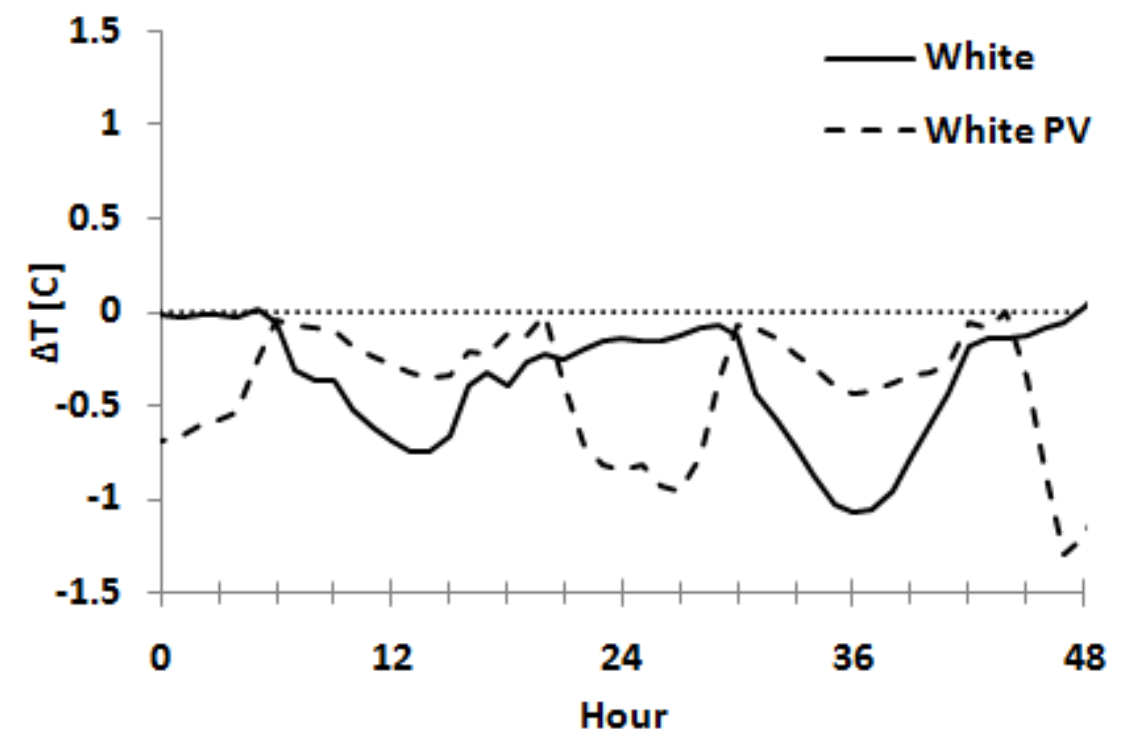

Figure 35: Change in near-surface air temperature [C] for $8 / 22-8 / 23 / 2000$ compared to baseline roof albedo of 0.25 . 


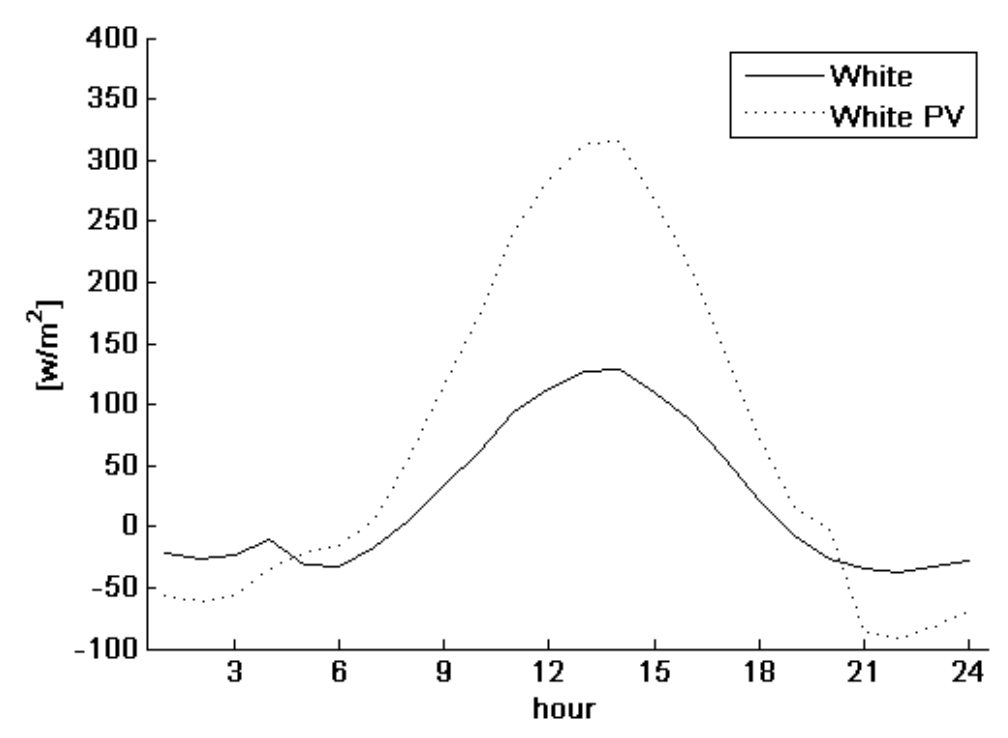

Figure 36: Typical flux profile of a white and white PV roof on a hot summer day.

If the switch to either green roofs or green PV roofs is considered, the modeled near-surface air temperatures of Figure 37 are predicted. In the case of an unshaded green roof, a decrease in daytime air temperatures of up to $1^{\circ} \mathrm{C}$ is predicted. However, the green roof model predicts elevated nighttime temperatures on the order of $0.75^{\circ} \mathrm{C}$. This behavior is expected based on the green roof flux profile. Thermal mass in the green roof stores heat and prevents night time cooling of the roof surface below ambient air temperatures.

When the green PV roof is considered the results are slightly different. Daytime cooling is reduced due to the presence of PV panels. Daytime temperature reductions of approximately $0.5^{\circ} \mathrm{C}$ were observed. At night the PV panels do exhibit a cooling effect as seen on the white roof, but this is balanced 
by the thermal storage in the green roof. The predicted night time temperatures are 0.5 to $0.75^{\circ} \mathrm{C}$ higher than the baseline.

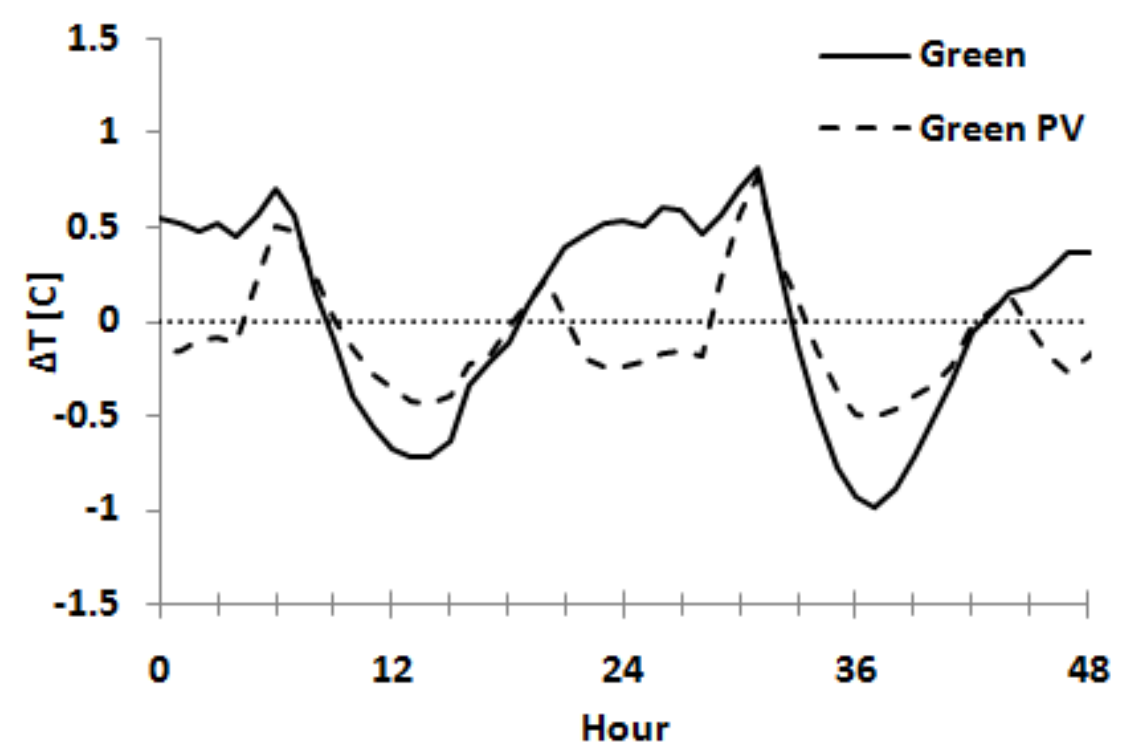

Figure 37: Change in near-surface air temperature [C] for 8/22-8/23/2000 compared to baseline roof albedo of 0.25 .

Results of this modeling effort can be compared with previous studies that used mesoscale modeling to predict the impact of various heat island mitigation strategies. In [41] the authors used the CSUMM mesoscale model to compare simultaneous increases in albedo and vegetation cover on air temperatures. This analysis was extended to 10 cities, with consideration given to the entire metro region of each city (not just city center). In that study a base case model was compared to the case of a 0.15 increase in vegetation fraction and albedo of modifiable surfaces. The area averaged changes to albedo and vegetation were 
approximately $5 \%$. The model predicted decreased temperatures of $0.5-1.5^{\circ} \mathrm{C}$ resulting from these changes.

Another study using CSUMM to analyze albedo and vegetation modification in the Los Angeles basin reports similar results [13]. In this case, increased albedo resulted in a $1.4^{\circ} \mathrm{C}$ decrease in air temperature in downtown Los Angeles. A similar reduction of $1.3^{\circ} \mathrm{C}$ was seen due to increased vegetation. Neither of these studies, which rely on simplified vegetation parameterizations, address the night time green roof penalty observed in the present study.

\section{Conclusions}

The methods developed to model unshaded and PV-shaded roof systems have been successfully validated with measured surface temperature data collected in Portland, OR (sections 4 and 6). Models were run for summertime conditions in six cities in 5 different climate zones to calculate sensible flux for each roof type. The sensible flux profile for various roof types in Portland, OR was also used as an input to the MM5 mesoscale model to calculate urban air temperature effects. The results can be broken down into three general categories: daytime UHI impacts, nighttime UHI impacts, and analysis of how PV panels influence the UHI. Similar results were seen across all 5 cities analyzed, so no attempt to differentiate the general conclusions is made. However, since the mesoscale modeling was only conducted for Portland, air temperature results should not be assumed universal across all cities. Each city has its own local 
weather patterns which play an important role in UHI formation. Despite this, the relative comparison of roofing technologies is still relevant in all climates.

\subsection{Daytime Impacts}

Across all six cities, the black roof and black-PV roof have the highest total daily sensible flux levels, with an average value ranging from 331 to $405 \mathrm{~W} / \mathrm{m}^{2}$. When the unshaded black roof flux levels are used as a reference for comparison, a consistent trend emerges for each city. If a black roof is replaced by either a white roof or a green roof, the peak flux is reduced by approximately $70 \%$, while the total daily flux is reduced by approximately $80 \%$ with a white roof and $52 \%$ with a green roof.

Mesoscale modeling in Portland, OR shows that a switch to white roofs resulted in a maximum daytime temperature reduction of approximately $1^{\circ} \mathrm{C}$ on a hot day where the maximum ambient temperature reached $30^{\circ} \mathrm{C}$. A similar switch to green roofs also resulted in a daytime reduction of about $1^{\circ} \mathrm{C}$. If all roofs were switched to white or green PV, a maximum daytime temperature reduction of less than $0.5^{\circ} \mathrm{C}$ is predicted. 


\subsection{Nighttime Impacts}

Across all of the metrics, the green roof exhibits higher total daily flux levels than a white roof. This is attributed to the green roof thermal mass, which prevents the roof from cooling below ambient temperatures at night. As a result, the green roof flux is usually positive (into the urban atmosphere), while the black and white roofs have negative fluxes at night.

Mesoscale modeling results for Portland indicate only a small difference in nighttime temperatures when white roofs are used in place of the baseline. Since traditional roofs do not have significant heat capacity, their color is of minor importance after sundown. When the case of white PV roofs is considered, there is a nighttime cooling of approximately $1^{\circ} \mathrm{C}$. This is caused by the increase in rooftop surface area that is capable of cooling below the ambient air temperature, thereby acting as a heat sink to the surrounding air. When the baseline roof is replaced with an unshaded green roof, nighttime temperatures are increased by approximately $0.75^{\circ} \mathrm{C}$. Similar results were seen for the green PV roof.

While the results of this study may indicate that a white roof can mitigate the summertime urban heat island more effectively than a green roof, it should be noted that only one green roof configuration was modeled. The model attempted to replicate a "typical" green roof; however, green roofs can vary widely from one building to another. Altering the plant characteristics, soil depth and irrigation specifications would impact the sensible flux characteristics of a green roof. 


\subsection{PV Impacts}

When PV panels are added to a black roof, there is a negligible impact on the peak flux; however, the total flux is reduced from unshaded black roof levels by approximately $11 \%$. Compared to the flux for an unshaded black roof, the white-PV roof has a peak flux reduction of approximately $40 \%$, and a total flux reduction of $55 \%$. The green-PV roof has a peak reduction of approximately $45 \%$ and a total flux reduction of about $42 \%$.

Mesoscale modeling results indicate that both the white and green PV roofs reduced daytime near surface air temperatures $0.4-0.5^{\circ} \mathrm{C}$ below the baseline case. More significant reductions on the order of $1^{\circ} \mathrm{C}$ are predicted for the white PV roof at night. The addition of PV panels to the urban energy balance adds a surface that is capable of cooling below ambient air temperatures at night, thereby cooling the surrounding air slightly. When a green roof is used, this effect is negated by the thermal storage in the green roof.

\section{Future Work}

In the case of PV shaded green roofs, this study revealed a substantial reduction in soil surface temperature. The magnitude of this reduction is expected to be sensitive to plant density and moisture availability in the soil. With further analysis, it would be interesting to consider the effect of PV panels on the health of a green roof. Preliminary observations of the PV shaded green roof at Portland State suggest that the shaded green roof is healthier than an unshaded roof. This is likely due to a decrease in extreme temperatures, and the associated retention of additional water in the roof. It would be informative to 
consider the changes in a number of green roof parameters; both in regards to the influence of PV shading on the roof, as well as the influence of the roof on building energy consumption and performance.

Additional work may also be helpful in evaluating the diurnal impact of PV panels. The discovery of apparent nighttime cooling due to PV panels should be analyzed with additional modeling. In addition to PV panels, other low mass building elements (perhaps high albedo panels) should be considered for their nighttime cooling potential. A similar modeling approach could be used to evaluate the maximum cooling potential of adding low mass building elements.

When analyzing the impacts of green roofs and increased urban vegetation, only the sensible flux was considered. The impact of latent flux should also be analyzed. Increases in latent flux may increase energy use for air conditioning, and could increase relative humidity influencing thermal comfort. For green roofs particularly, an increase in latent flux on the rooftop could have an undesirable impact on the intake air to rooftop cooling systems.

The mesoscale modeling used in this study was helpful in assessing the relative differences between roof types in Portland. It would be beneficial to extend this modeling to other cities, as well as to winter weather conditions. Additionally, the results of this study revealed a nighttime increase in temperature due to green roofs. Although this finding appears to be physically based, it has not been predicted by previous mesoscale modeling efforts. Additional research should be conducted to explore the differences between the fluxes derived from the EnergyPlus green roof model, and those predicted with mesoscale vegetation 
parameterizations. Perhaps the EnergyPlus model could ultimately be coupled with a mesoscale modeling package to improve the accuracy of urban rooftop vegetation parameterizations. 


\section{References}

[1] Oke, T.R., Boundary Layer Climates. 2nd ed. 1987, London: Methuen.

[2] Konopacki, S., Akbari, H., Energy savings of heat island reduction strategies in Chicago and Houston (including updates for Baton Rouge, Sacramento, and Salt Lake City), Lawrence Berkeley National Laboratory Report LBNL-49638, 2002.

[3] Luber, GE., Sanchez, CA., Heat Related Deaths - United States, 19992003. Center for Disease Control Morbidity and Mortality Weekly Report, 2006. 55(29): p. 796-798.

[4] McGeehin, MA., Mirabelli, M., The Potential Impacts of Climate Variability and Change on Temperature Related Morbidity and Mortality in the United States. Environmental Health Perspectives, 2001. 109(2): p. 185-189.

[5] Taha, H., Modeling the Impacts of Large Scale Albedo Changes on Ozone Air Quality in the South Coast Air Basin. Atmospheric Environment, 1997. 31(11): p. 1667-1676.

[6] Taha, H., Meso-urban meteorological and Photochemical Modeling of Heat Island Mitigation. Atmospheric Environment, 2008. 42(1): p. 8795-8809.

[7] Akbari, $\mathrm{H}$. and S. Konopacki, Calculating energy-saving potentials of heatisland reduction strategies. Energy Policy, 2005. 33(6): p. 721-756.

[8] Lin, Y.-J. and H.-T. Lin, Thermal performance of different planting substrates and irrigation frequencies in extensive tropical rooftop greeneries. Building and Environment, 2011. 46(2): p. 345-355.

[9] Sonne, J., Evaluating green roof energy performance. ASHRAE Journal, 2006. 48(2): p. 59-61.

[10] Akbari, H., S. Konopacki, and M. Pomerantz, Cooling energy savings potential of reflective roofs for residential and commercial buildings in the U.S. Energy, 1999. 24(5): p. 391-407.

[11] EIA, Electric Power Annual 2009. 2011. p. 108.

[12] Jo, J.H., J.D. Carlson, J.S. Golden, and H. Bryan, An integrated empirical and modeling methodology for analyzing solar reflective roof technologies on commercial buildings. Building and Environment, 2010. 45(2): p. 453-460. 
[13] Sailor, D.J., Simulated Urban Climate Response to Modifications in Surface Albedo and Vegetative Cover. Journal of Applied Meteorology, 1995. 34(7): p. 1694-1704.

[14] Sailor, D.J. and N. Dietsch, The urban heat island mitigation impact screening tool (MIST). Environmental Modelling and Software, 2007. 22: p. 15291541.

[15] Taha, H., Residential cooling loading and the urban heat island - the effects of albedo. Building and environment, 1988. 23(4): p. 271-283.

[16] Theodosiou, T., Green roofs in buildings: Thermal and environmental behaviour. Advances in Building Energy Research, 2009. 3(1): p. 271-288.

[17] Kosareo, L. and R. Ries, Comparative environmental life cycle assessment of green roofs. Building and Environment, 2007. 42(7): p. 26062613.

[18] Kumar, R. and S.C. Kaushik, Performance evaluation of green roof and shading for thermal protection of buildings. Building and Environment, 2005. 40(11): p. 1505-1511.

[19] Czemiel Berndtsson, J., Green roof performance towards management of runoff water quantity and quality: A review. Ecological Engineering, 2010. 36(4): p. 351-360.

[20] Sailor, D.J., D. Hutchinson, and L. Bokovoy, Thermal property measurements for ecoroof soils common in the western U.S. Energy and Buildings, 2008. 40(7): p. 1246-1251.

[21] DeNardo, J.C., A.R. Jarrett, H.B. Manbeck, D.J. Beattie, and R.D. Berghage, Stormwater mitigation and surface temperature reduction by green roofs. Transactions of the American Society of Agricultural Engineers, 2005. 48(4): p. 1491-1496.

[22] Getter, K.L. and D.B. Rowe, The role of extensive green roofs in sustainable development. HortScience, 2006. 41(5): p. 1276-1285.

[23] BES, Ecoroof incentives: Incentives for ecoroof construction in Portland, http://www.portlandonline.com/bes/index.cfm?c=48724\&, 2010.

[24] Toronto, C.o., Green roof bylaw, in Municipal Code, Chapter 492. 2010.

[25] Niachou, A., K. Papakonstantinou, M. Santamouris, A. Tsangrassoulis, and G. Mihalakakou, Analysis of the green roof thermal properties and 
investigation of its energy performance. Energy and Buildings, 2001. 33(7): $p$. 719-729.

[26] Theodosiou, T.G., Summer period analysis of the performance of a planted roof as a passive cooling technique. Energy and Buildings, 2003. 35(9): p. $909-917$.

[27] Santamouris, M., C. Pavlou, P. Doukas, G. Mihalakakou, A. Synnefa, A. Hatzibiros, and P. Patargias, Investigating and analysing the energy and environmental performance of an experimental green roof system installed in a nursery school building in Athens, Greece. Energy, 2007. 32(9): p. 1781-1788.

[28] Alexandri, E. and P. Jones, Temperature decreases in an urban canyon due to green walls and green roofs in diverse climates. Building and Environment, 2008. 43(4): p. 480-493.

[29] NREL, Solar technologies market report. 2008, US Department of Energy.

[30] Sailor, D.J., A green roof model for building energy simulation programs. Energy and Buildings, 2008. 40(8): p. 1466-1478.

[31] Torcellini, P., M. Deru, B. Griffith, K. Benne, M. Halverson, D. Winiarski, and D.B. Crawley, DOE Commercial Building Benchmark Models. 2008, National Renewable Energy Laboratory. p. 15.

[32] Wilcox, S. and W. Marion, User's manual for TMY3 data sets. 2008, National Renewable Energy Laboratory: Golden CO.

[33] ASHRAE, Standard 90.1: Energy Standard for Buildings Except Low-Rise Residential Buildings. 2007, American Society for Heating, Ventilation, and AirConditioning Engineers, Inc.: Atlanta, GA.

[34] DOE, EnergyPlus engineering reference - the reference to EnergyPlus calculations. 2007, U.S. Department of Energy. p. 868.

[35] LBNL, Cool roofing materials database, http://eetd.lbl.gov/CoolRoofs/, 2000.

[36] ASTM, Standard test method for solar absorptance, reflectance, and transmittance of materials using integrating spheres. 1996, American Society for Testing and Materials. p. 9.

[37] Grell, G. A., Dudhia, J. and Stauaer, D. R. (1995) A description of the Fifth Generation Penn State/NCAR Mesoscale Model (MM5). 1995, NCAR Technical Note, NCAR/TN-398\#STR: p. 1-122. 
[38] Fan, H., Sailor, D.J., Modeling the Impacts of Anthropogenic Heating on the Urban Climate of Philadelphia: a Comparisons of the Implementation in two PBL Schemes. Atmospheric Environment, 2005. 39(1): p. 73-84.

[39] Akbari, H., Rose, L.S. and Taha, H., Analyzing the land cover of an urban environment using high-resolution orthophotos. Landscape and urban Planning, 2003. 63(1): p. 1-14.

[40] National Weather Service Station - PDX International Airport.

[41] Taha, H., Konopacki, St. and Gabersek, S., Impacts of Large-Scale Surface Modifications on Meteorological Conditions and Energy Use: A 10-

Region Modeling Study. Theoreticl and Applied Climatology, 1999. 62(1): p. 175185.

[42] Grell, G., Dudhia, J., Stauffer, D., A description of the fifth generation Penn State/NCAR Mesoscale Model (MM5), 1994. NCAR Tech. Note NCAR/TN-398, $117 \mathrm{pp}$. 